\title{
DOWN BUT NOT OUT: SUPINE POSTURES AS FACILITATORS OF PLAY IN DOMESTIC DOGS
}

\author{
KERRI M. NORMAN \\ Bachelor of Arts, University of Lethbridge, 2011
}

\author{
A Thesis \\ Submitted to the School of Graduate Studies \\ of the University of Lethbridge \\ in Partial Fulfillment of the \\ Requirements for the Degree
}

MASTER OF SCIENCE

Department of Psychology

University of Lethbridge

LETHBRIDGE, ALBERTA, CANADA

(C) Kerri M. Norman, 2014 
DOWN BUT NOT OUT: SUPINE POSTURES AS FACILITATORS OF PLAY IN DOMESTIC DOGS

\author{
KERRI NORMAN
}

Date of Defence: August 29 $9^{\text {th }}, 2014$

Dr. Louise Barrett

Professor

Ph.D.

Supervisor

Dr. Peter Henzi

Professor

Ph.D.

Co-Supervisor

Dr. Sergio Pellis

Professor

Ph.D.

Thesis Examination Committee

Dr. Scott Allen

Associate Professor

Ph.D.

Chair, Thesis Examination Committee 


\begin{abstract}
Research has shown that unlike wolves, dogs do not form stable packs and so do not function within a social hierarchy (Bradshaw, 2011). Therefore it is not clear that rolling onto the back can be readily interpreted as submission in dogs. In order to discern the function of rolling over during play in dogs, rollovers that occurred during playful dyadic interactions were analyzed using Eshkol-Wachman movement notation, a globographic system for recording, frame-by-frame, the coordinated movements of the interacting partners, to identify the locations of the body bitten and the context within which rollovers occur. It was discovered that there exists three distinct ways that dogs can end up on their backs during play. Rolling over can be used for the solicitation of play, to avoid being bitten (defense), and to deliver a bite (offense). These findings demonstrate that rolling over in dogs is a flexible and context dependent strategy for the facilitation and continuation of play, rather than a behaviour that is governed by the existence of a rigid hierarchy, and so signifying submission.
\end{abstract}




\section{Acknowledgements}

First, I would like to recognize my husband, Adam Walser for always having words of encouragement at the ready whenever I became discouraged. I am also grateful to my family, who supported me, financially and otherwise through what appeared to be an endless educational endeavour. I would like to thank my supervisors, Dr. Peter Henzi, Dr. Sergio Pellis and Dr. Louise Barrett. Words cannot describe how grateful I am to have your support. Without your enduring patience and guidance I would not be where I am today. Lastly, I want to thank the Keith and Hope Ferguson Memorial Scholarship fund for helping fund my studies. 


\section{Contents}

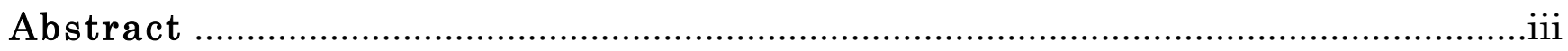

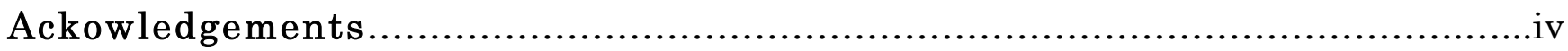

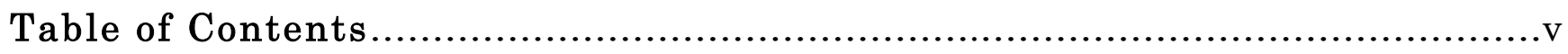

List of Tables..............................................................................

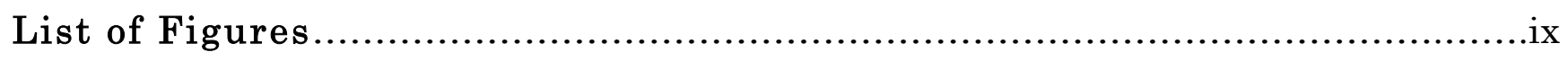

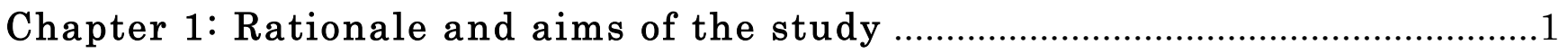

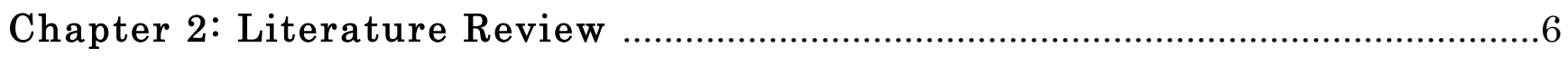

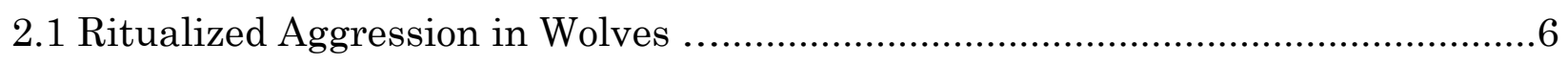

2.2. Feral and Free-Range Village Dog Social Organisation.....................................11

2.3. Social Dominance in the Domestic Dog.............................................................12

2.4. Dominance and Aggression in the Domestic Dog: The 'Bone-in-Pen' Test ........14

2.5. Behavioural and Morphological Changes Due to Domestication in the Dog......15

2.6. Behavioural Variation: The Predatory Sequence in the Domestic Dog ............16

2.7. Effects of Domestication on the Dog: Paedomorphism and Signal Ambiguity...18

2.8. A Note on Behavioural Similarities Between the Domestic Dog and the Wolf..19 
2.9. Morphological Differences Between the Domestic Dog and the Wolf...............20

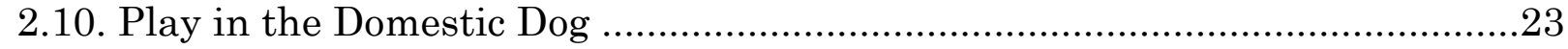

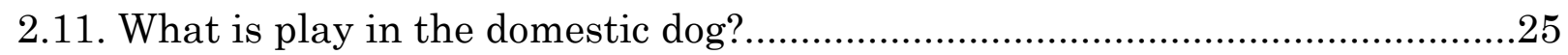

2.11. The Facilitation and Maintenance of Play …...............................................25

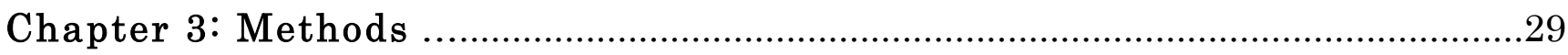

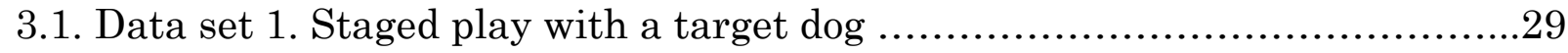

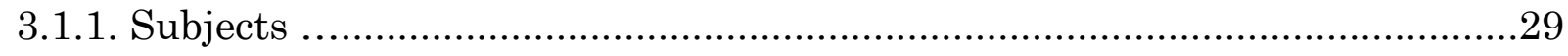

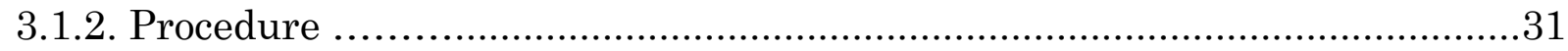

3.2 Data set 2. YouTube videos of playing dogs ..................................................31

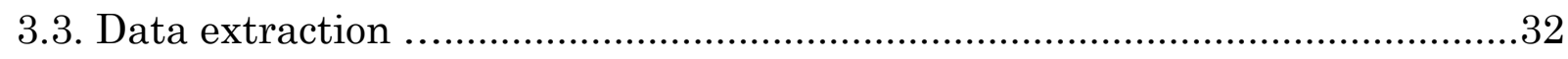

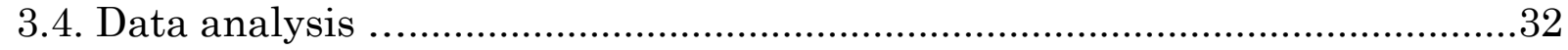

\section{Results}

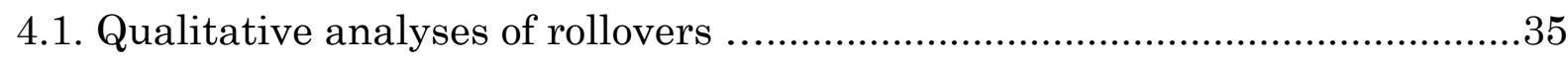

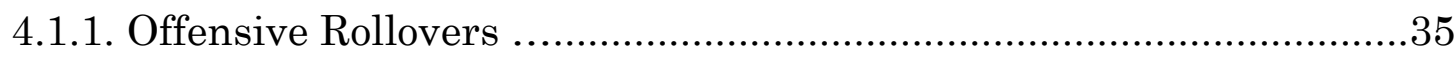

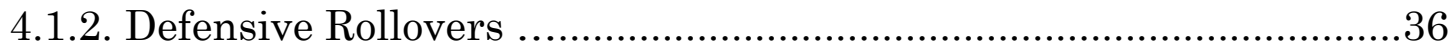

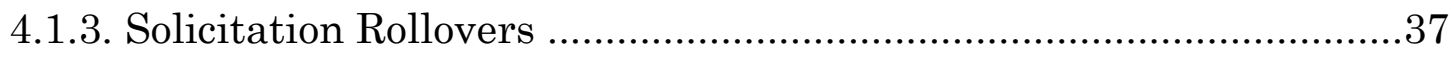

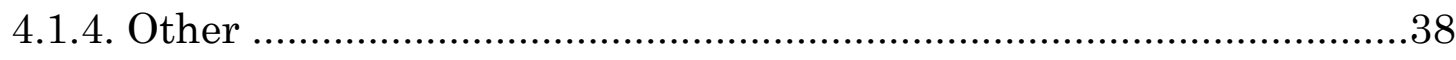

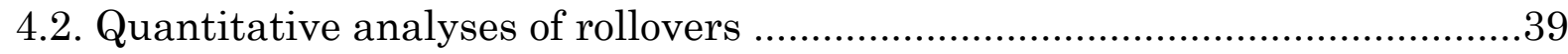

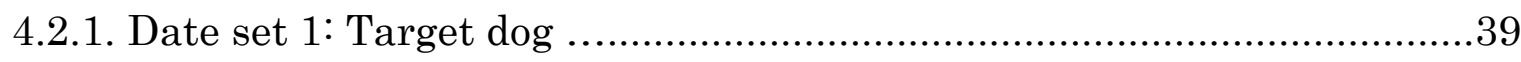

4.2.1.1. Aggression and the occurrence of play ............................................39

4.2.1.2. The occurrence of rollovers during play ..........................................39 
4.2.1.3. Duration of the supine phase of the rollover

4.2.2. Data set 2: YouTube dogs ..................................................................41

4.2.2.1. The occurrence of rollovers during play .........................................41

4.2.2.2. Duration of the supine phase of the rollover ...................................42

4.2.3. Duration of the supine phase …..........................................................

4.3. The frequency of different types of rollovers ..............................................44

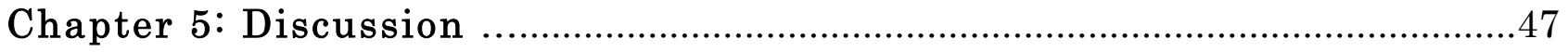

\section{Chapter 6.}

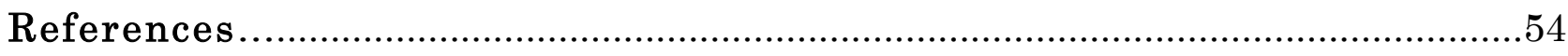




\section{List of Tables}

Table 1. Identity and characteristics of dogs used in the first study

Table 2. The relationship between play bout duration and the height of play partners on the probability that a play bout will contain at least one rollover .40

Table 3. The relationship between the height of play partners relative to the target dog and the duration of the supine phase of the rollover

Table 4. The relationship between the relative size of play partners and the duration of the play bout on the frequency with which play bouts were performed

Table 5. The effects of the relative size of play partners (similar, dissimilar) on the duration of the supine phase of the rollover

Table 6. The effect of relative partner size on the duration of the supine phase of the rollover in dyads of dissimilarly sized dogs 


\section{List of Figures}

Figure 1. Photographs illustrating a play sequence that contains an offensive

rollover

.36

Figure 2. Photographs illustrating a sequence that contains a defensive rollover

Figure 3. Photographs illustrating a sequence that contains a rollover being used to solicit play.....

Figure 4. The relationship between the duration of the play bout and the likelihood that it will contain a rollover. .40

Figure 5. The frequency distributions of the duration of the supine phase of the rollover

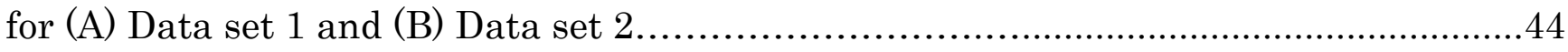

Figure 6. The percentages of the five possible forms of rollovers for the two data sets 


\section{Chapter 1: Rationale and aims of the study}

The domestic dog (Canis lupus familiaris) is a subspecies of the gray wolf (Canis lupus) that expresses high phenotypic diversification as a consequence of driving artificial selection by humans (Wayne et al. 1999). The relatively recent origin of the taxon (Freedman et al. 2014) has, in part, given rise to the assumption that the behavioural profile of domestic dogs (dogs, hereafter) is broadly mappable onto that of wolves (Mech 1970, Bekoff 1972, Abrantes 2005).

An inherent issue with applying wolf behavior to dogs is that it fails to take into consideration the effects of domestication on behaviour and morphology. Studies on other species of animals have demonstrated that domestication can substantially affect behaviour. Robinson et al. (1990) and Ruzzante et al. (1993) studied captive-bred fish and reported a reduction in agonistic behaviour with domestication. Ruzzante (1994) speculated that changes in aggressive behaviour were correlated with selection for growth rate in captivity. If food is limited, the larger and more aggressive fish will be better able to compete for existing resources (Price, 1999). It has also been found that domestication has altered the threshold for aggressive behaviour in captive bred Norway rats (Rattus norvegicus). Norway rats in captivity have not lost the potential for aggression towards members of their own species but, even with a significant decrease in living space, they do not regularly resort to aggression (Price, 1999). One hypothesis is that the threshold for aggressive behaviour in laboratory rats is raised as a consequence of their being reared and housed with peers in small cages (Price, 1999). It has also been found that in accordance with the changes in the frequency and intensity of aggressive behaviours in domestic animals, there is an associated decrease in the frequency and 
intensity of submissive behaviour (Price, 1999). This may reflect higher thresholds for aggressive behaviour. The uninhibited manner in which domestic Norway rats interact is substantially different than the cautious and ambivalent nature of wild Norway rats (Price, 1999). Furthermore, studies comparing wild and domestic house mice found that domestic mice interacted more frequently than wild mice and were more likely to interact with dominant individuals (Price, 1999). These results raise the possibility that domestication can lead to the relaxation in the roles associated with hierarchies.

Domestication not only alters the behaviour of animals, but can also have a drastic effect on morphology. In a study conducted in Russia over the course of 40 years, Silver foxes, Vulpes vulpes bred for tameness, began to resemble domestic dogs in their morphology (pied coats and floppy ears) and behaviour, while the control population continued to exhibit wild-type morphology and behaviour, including strong defensive responses towards humans (Price, 1999).

Researchers studying the social behaviour of the dog have found that domestication and artificial selection have altered their behaviour and morphology from that of their ancestor, the wolf (Lindsay, 2000; Coppinger et al. 2001; Van Kerkove, 2004; Bradshaw et.al., 2009; Horowitz, 2009). Dogs have been artificially selected for various jobs, such as hunting and herding, which has led to some breeds only displaying segments of the wolftypical behaviour pattern (Coppinger et al. 2001). For example, breeds required to work in close association with animals, such as sheep and cattle, have been bred to exhibit the orient, eye, stalk, and chase aspects of the wolf motor sequence, and have had the 'kill' portion of the sequence removed through selective breeding (Coppinger et al. 2001). In contrast, terriers that have been bred for chasing and killing small rodents possess the full predatory sequence (Coppinger et al. 2001). Thus, within dogs, there exists a wide variability in motivations and behaviour which is thought to have an impact on the dog's 
ability to communicate effectively with one another (Bradshaw et. al., 1999; Lindsay, 2000; Horowitz, 2010).

The loss of ancestral resemblance has further complicated the dog's ability to communicate with one another. The morphology of the wolf is fine-tuned for the communication of 'dominant' and 'subordinate' status (Mech, 1970; Fox, 1971). The long sweeping tail of the wolf is ideal for being held high above the horizontal plane of the back in a dominant display, or for being tucked tightly between the legs during submission (Schenkel, 1967, Abrantes, 2005). The ears of the wolf are capable of a wide range of movement and can be held in a variety of positions, all of which are indicative of varying states of arousal (Schenkel, 1967; Mech, 1970; Abrantes, 2005). In contrast, due to domestication and artificial selection, some dogs are no longer able to effectively display many of the signals associated with 'dominance' and 'submission' (Bradshaw et. al, 2009; Horowitz, 2010), such as flattening the ears or tucking the tail between the legs (Schenkel, 1967). This is because domestication and selective breeding have resulted in ears and tails that no longer resemble their ancestral form and are no longer capable of displaying the same degree of movement as the wolf (Bradshaw et. al., 2009; Horowitz, 2010).

Morphological variability, coupled with behavioural changes, have lead researchers to question the usefulness of the application of wolf-typical behaviour to the behaviour of the dog. The high degree of behavioural and morphological variability within the domestic dog species means that the domestic dog is presented with the challenge of communicating effectively with conspecifics, while avoiding the onset of aggression. For example, if dogs use wolf postures and behaviours to regulate social interactions, then pugs, with their tightly curled and immovable tail, small inflexible ears, and flattened faces are at a significant disadvantage communication-wise in contrast to Siberian huskies, which have maintained the appearance of the wolf and are able to display the full set of wolf-typical behaviours and postures (Bradshaw, 2011). 
Aggressive interactions between wolves (Mech 1970) are associated with a suite of ritualized agonistic displays that serve to curtail active aggression by signaling dominance and subordination. One famous exemplar of the latter is the 'rollover' (Lorenz 1942), whereby a subordinate animal rolls over onto its back, often spontaneously, in an act of 'passive submission' or appeasement (Packard 2003) that inhibits attack by the dominant one. This behaviour is coupled with other distinct postures and behaviours, indicative of ritualisation, that include flattened ears, curved spine, tucked tail, reduced mobility and averted gaze (Schenkel 1967; Mech 1970, Abrantes, 2005).

Despite observed differences in social organisation (Pal et al. 1998, Boitani et al. 2007), including the failure to observe the strong dominance relationships thought to be characteristic of wolf packs (Bradshaw et al. 2009), the observation that rollovers occur during play-fighting in dogs has also been assumed to indicate submission, and has led to their being used to identify play partners as dominant or subordinate (Fox 1969; Bauer et al. 2007, Ward et al. 2008). This suggests that, in the context of play-fighting, rollovers serve to prevent a shift to aggression, either by terminating the bout before escalation occurs, or by allowing the engagement to be recalibrated so that play can continue.

There are at least two other possibilities that may account for the occurrence of rollovers during play. First, self-handicapping by a larger or more dominant animal has been reported as means of soliciting play (Bekoff, 1974; Palagi, 2008), with rolling over onto the back in front of the potential play partner being one such gesture (e.g., LeResche, 1976; Pellis et al. 2014). Second, in both dogs and canids more generally, the nape of the neck, the throat and the snout (Aldis, 1975; Bekoff, 1976; Fox, 1969) are gently bitten during play fighting, and rolling over may be used as a combat tactic, either by the defender to block access to the play target or by the attacker to gain access to the 
target. Such combat uses of rollovers have also been reported in the play fighting of noncanid species of mammals (e.g., Pellis et al. 1987; Pellis et al., 2014).

If rollovers during play are acts of submission, then we would expect them to be (i) triggered by behaviour that is overly aggressive or that causes detectable discomfort or pain, (ii) performed predominantly by one of the play partners, who will be disadvantaged by being smaller or weaker, and (iii) the supine position will be sustained, thereby (iv) inhibiting the play behaviour or aggression of the other animal. If, on the other hand, they are executed tactically, for combat purposes, then they should (i) be triggered by an attack and (ii) serve to block it or (iii) lead to an immediate attack or counter-attack. They are therefore either likely (iv) to be performed by either partner or (v) by the larger animal in the context of soliciting play. They will therefore (v) not inhibit the continuation of play. Finally (vi), if used for playful solicitation, rather than inhibiting attack, rollovers should elicit playful attack by the nearby partner. To test these predictions, I collected and analyzed two sets of videotaped footage of the play bouts of adult dogs. 


\section{Chapter 2: Literature Review}

In many species, rough-and-tumble play consists of modified behavioural elements of direct aggression that include those behaviour patterns used to threaten and contact opponents (Pellis et al., 1996). When animals use behaviours derived from aggression they run the risk of their partner misinterpreting their behaviour as overt aggression. In the dog, play includes such behaviours as; growling, forced downs, inhibited biting (where individuals refrain from inflicting injury to their partner), and various facial expressions associated with offensive and defensive threat (Bekoff, 1974; Bekoff et al. 1981; Burghardt, 2005; Ward et al. 2008). In the domestic dog where opponents can vary dramatically in body size and shape, the question arises how interactants balance competition with cooperation during play, while at the same time avoiding the onset of aggression. It has been proposed that in order to avoid aggression, dogs rely on ritualized behaviours derived from hierarchy formation and maintenance in wolves (Bekoff 1972; Bauer et al. 2007).

\subsection{Ritualized Aggression in Wolves}

Wild wolf packs are familial groups comprised of a mated pair and their offspring and are arranged in male and female linear dominance hierarchies (Mech, 1999; Abrantes, 2005). Although harmony is the rule, conflicts can arise during times of increased stress (for example, when a member dies or emigrates). In terms of inclusive fitness and energy expenditure, fighting is costly and wolves require a mechanism for the resolution of conflicts should they arise (Lorenz, 1954; Schenkel, 1967; Mech, 1999; Abrantes, 2005). A mechanism for managing intraspecific aggression is the ritualization of facial 
expressions, gestures, body postures, and vocalizations used in non-aggressive contexts for use during aggressive encounters (Lorenz, 1954; Schenkel, 1967; Bekoff, 2002). A ritualized behaviour used by wolves is rolling over into a supine position, also called 'passive submission' (Schenkel, 1967). Passive submission occurs when an inferior individual is faced with a wolf asserting and/or displaying its dominance. During passive submission, a wolf rolls over on to its back or one side with its tail tucked between its legs, with its gaze directed away from the other animal, lips drawn back into a 'grin' and uppermost hind leg elevated to expose the genitalia (Lorenz, 1954; Schenkel, 1967; Mech, 1970, Fox, 1971). If the subordinate individual rolls over prior to the approach of the dominant wolf, it will remain passive as the dominant wolf approaches and is finished sniffing and/or inspecting it (Schenkel, 1967). Occasional licking of the air and nosing movements are made by the passive individual, but usually it remains quite motionless during lateral recumbency (Fox, 1971). Movement of the submissive wolf is inhibited by the presence of the dominant wolf and any sudden movement generally results in immediate assertion of dominance in the form of standing over, growling or pinning (Fox, 1971). Lying supine is assumed to be a ritualized form of cub behavior, derived from the inguinal inspection of the cub by its mother (Schenkel, 1967; Mech, 1999; Abrantes, 2005). This use of ritualized cub behaviour to defer to a stronger or more dominant wolf has been argued to allow a subordinate individual to signal its status effectively and constrain the intensity of aggression, thus maintaining the cohesion of the group (Fuller et al., 1962; Schenkel, 1967; Zimen, 1982; Abrantes, 2005).

Postures convey information regarding a wolf's stature and ability to fight (Schenkel, 1967; Mech, 1999). There is a genuine relationship between fighting ability and size that cannot be faked as larger wolves have a greater chance of winning serious fights (Mech, 
1999; Harrington et al., 2003; Fatjo et. al., 2007). In wolves, signals of 'dominance' and 'submission' are the consequence of various combinations of motor capacities including the coordinated activity of the face, head, back, tail, and anal area (and may include whimpering and growling) (Scott, 1950; Mech, 1970). The position of a wolf's peripheral parts during an interaction is a good indicator of the animal's social status (Mech, 1999). The following section will outline the anatomy of the wolf associated with displays of dominance and submission.

Fur

The fur of the wolf is coloured in ways that highlight specific modes of expression. The white on the edges of the ears flag their position in space, while the lighter eyebrows help make submissive grins and agonisitic puckering more visible (Mech, 1999; Abrantes, 2005). Furthermore, the wolf's chest and abdomen are generally much lighter in colour than the back. When a wolf rolls over in submission, the light underside helps in flagging the behaviour (Schenkel, 1967; Fox, 1971; Mech, 1999; Abrantes, 2005). Lastly, the rump and hackles of the wolf consist of hair that is coarse and thick, which when raised, stands above the rest of the coat (Fox, 1971; Mech, 1970). The hackles are raised during aggressive interactions and are a good indicator of arousal (Mech, 1999).

\section{Face}

One of the most important loci of visual signals of the wolf is the head. The facial muscles are capable of considerable movement and are useful in expressing various states of arousal (Scott, 1956). The interaction of the colouring of the face and function of 
the facial muscles coupled with the activity of the eyes, ears, and nose allows for subtle and unambiguous visual signals (Schenkel, 1967; Mech, 1970; Darwin, 1998).

\section{a. Mouth}

Dominance and self-assertion are characterized by an open mouth with the corners pulled forward in an agonistic pucker with bared teeth (Mech, 1970; Fatjo et. al., 2007). Agonistic puckering causes the normally smooth forehead to wrinkle. In contrast, submission and self-deflation are characterized by a closed mouth with the corners pulled far back in a submissive 'grin' (Schenkel, 1967). During a submissive grin, the teeth, which are the wolf's primary weapon, are hidden from view. A submissive individual has a characteristic smooth forehead with slit-like eyes (Fox, 1970; Mech, 1999; Fatjo et. al., 2007).

\section{b. Ears}

The ears of the wolf can be held erect or depressed, with varying degrees inbetween these two extremes (Fox; 1970; Mech, 1999). Dominance and self-assertion are characterized by the ears being held erect or slightly forward (Schenkel, 1967; Fox, 1970; Mech, 1999; Abrantes, 2005). In contrast, submission and self-deflation are characterized by the ears being held flat against the head (Schenkel, 1967; Fox, 1970; Mech, 1999; Abrantes, 2005). Lastly, ears that are held in a partially lowered position are characteristic of ambivalence and not indicative of any particular rank (Fatjo et. al., 2007). 


\section{c. Tongue}

Tongue flicking occurs when the tongue is rhythmically thrust between the teeth and is a behaviour primarily seen in wolves experiencing stress (Mech, 1999; Fatjo et. al., 2007). Fox (1970) described the licking of the lips as a behaviour exhibited by submissive

individuals. Beaver (1999a), Harrington et al., (2003) and Fatjo et al. (2007), observed tongue flicking in all members of the pack regardless of rank and found that the behaviour is a clear indicator of conflict.

\section{Tail}

The position of the tail is a reliable indicator of social status in wolves (Harrington et al., 2003; Fatjo et. al., 2007). The tail may be moved up or down and may be wagged from side to side (Fox, 1970, Mech, 1970; Fatjo et. al., 2007; Abrantes, 2005). Similar to the ears, tail posture can vary between two extremes. During displays of dominance and self-assertion the tail is held level or raised above the plane of the back (Mech, 1999). Often the raised tail is accompanied by a slow wag. In contrast, during submission and self-deflation the tail is held very low, often tucked between or curved alongside the legs (Mech, 1999; Abrantes, 2005; Fatjo et. al., 2007). During periods of reduced social tension, the tail hangs loosely from a raised base, either in a convex or a concave curve (Mech, 1999). The position of the tail in relation to the anal region is also an important indicator of inner state. During dominance and self-assertion the position of the tail exposes the anal region allowing the individuals scent to be carried and is considered a 'flagging behaviour'. In contrast, during submission and self-deflation the tail tightly covers the anal region masking the individuals scent (Mech, 1999). 


\subsection{Feral and Free-Range Village Dog Social Organisation}

Many of the behaviours and postures associated with hierarchy formation and maintenance in wolves are not readily utilized by dogs as has been shown in studies conducted on feral village dogs (Coppinger et al., 2001). Feral and free ranging dogs are domestic dogs that have minimal contact with, or dependence on humans (Boitani et al., 2007). Van Kerkhove (2004) reviewed five studies on feral dogs published from 1975 to 1995 and concluded that, unlike wolves, the pack structure of feral dogs is loose and rarely involves cooperation, either in raising young or in obtaining food. Bradshaw (2009) reviewed a series of studies of feral dogs in West Bengal conducted by S.K. Pal and colleagues (Pal et. al., 1998, 1999; Pal, 2003, 2005), who were able to identify coherent social groups consisting of primarily close kin that shared and defended communal territories (Bradshaw, 2009; Pal et. al., 1998).

Although feral dogs form coherent and distinguishable groups similar to wolves, Pal and colleagues noted marked differences in feral dog behaviour in regards to sexual and parental behaviour (Bradshaw, 2009). According to Pal and colleagues, female feral dogs were courted by up to eight males which competed for mating opportunities and as a result, copulatory ties with several males on the same day were not uncommon (Pal et. al., 1999). In feral dogs, pair bonds were formed after the establishment of family groups, which is in contrast to the organization of wolves where the pair bond is the foundation of the hierarchy. Furthermore, while dominant female wolves attempt to monopolize males, aggression between female feral dogs is rare (Bradshaw, 2009). It is not uncommon for there to be more than a single breeding female in a group of feral dogs. The lack of reproductive suppression in feral dogs differs from wolves where, if more than two females produce pups in a given season, infanticide by females results in the survival of 
only a single litter (Packard, 2003; Bradshaw, 2011). In contrast, infanticide in groups of feral dogs is rare (Boitani et. al., 2007; Bradshaw, 2009). Lastly, Pal and colleagues (1998, 1999) concluded that agonistic encounters in feral dogs did not adhere to the behavioural paradigm of wolves. Although ritualized behaviours such as 'dominance' and 'submission' sometimes occurred within and between groups of feral dogs, they were not reserved solely for group cohesion as is the primary function in wolves (Bradshaw, 2009). It appears that domestication has altered the social behaviour of dogs to the extent that when they are provided with the opportunity to interact freely they do not form dominance hierarchies like their closest relation, the wolf (Bradshaw, 2009).

If it is the case that feral dogs do not strictly adhere to the wolf behavioural paradigm of hierarchy formation and maintenance, then it is unlikely that the domestic dog, which has been altered by human interference, behaves exactly like the wolf (Serpell, 1995). Bradshaw (2009) points out that unlike feral dogs, domestic dogs are usually spayed or neutered, which appears to disrupt sociality further still, to the point where hierarchies may no longer be discernible. As a result, it calls into question the usefulness of the application of wolf behaviour when attempting to explain the behaviour of the dog (Lindsay, 2000; Bradshaw, 2009).

\subsection{Social Dominance in the Domestic Dog}

The social behaviour of the dog is conventionally described in terms of the signals performed by the wolf during dominance/submission interactions within the pack (Scott et al.,1965; Bekoff, 1974; Goodwin et al., 1997; Bauer et al., 2007, Ward et al., 2008). This assumes that over the course of domestication, the behavioural repertoires of the wolf and the dog have not diverged. As Goodwin et al. (1997) state, this assumption may be 
valid for breeds of dog that have retained a wolf-like appearance. However, in many modern breeds, such as the Cavalier King Charles spaniel, most or all of the ancestral structures used for signaling (muzzle, ears, and tail) have been heavily modified by artificial selection (Goodwin et al., 1997). Scott et al. (1965) prepared an ethogram of dog behaviour and examined the available descriptions of the behaviour of the wolf and found the majority of patterns displayed by wolves were also displayed by dogs. However, a major behaviour pattern of wolves that was not reported in dogs is that of a dominant animal pinning a subordinate one to the ground by the neck, a behaviour pattern characterized by a lateral recumbent posture of the submitting individual (Scott et al., 1965). Current research has raised questions regarding the validity of the application of wolf-typical behaviour to dogs including the wolf's propensity to form hierarchies (Serpell, 1995; Mech, 1999; Coppinger et al., 2001; Lindsay, 2000; Horowitz, 2010; Bradshaw, 2009). Bradshaw (2009) concludes that by applying wolf behaviour to the domestic dog, we fail to take into consideration the marked effect of domestication and artificial selection on morphology and behaviour of the dog. Bradshaw (2009) also suggests that the concept of dominance may only be important in the dog if individuals remain with the family group their entire life, as wolves do (Serpell, 1995; Bradshaw, 2009; Horowitz, 2010). 'Dominance', when applied to dogs, has been used repeatedly to describe the outcome of all contests, without specifying whether these are determined by an underlying social structure, or temporary asymmetries between pairs of individuals. Furthermore, the terms 'dominant' and 'submissive' are often inappropriately applied as characteristics of an individual dog rather than being used correctly to describe a relationship between two individuals. People who subscribe to the belief that dogs are behaviourally no different than wolves tend to extract and apply the 'hierarchy' 
component of wolf behaviour to the dog and ignore the social component from which it emerges (Horowitz, 2010). As a result, 'dominant' and 'submissive' tend to be misapplied as motivation for social interactions, rather than simply identifying a quality of that relationship (Schenkel, 1967; Bradshaw, 2009).

\subsection{Dominance and Aggression in the Domestic Dog: The 'Bone-in-Pen' Test}

Scott et al. (1965) conducted one of the first experiments on the dog measuring dominance, submission and hierarchy formation. In the experiment, a litter of puppies was placed in an enclosure with a bone. The puppy that acquired and maintained ownership of the bone was considered to be the 'dominant' puppy. On noting an increase in aggression and competition, Scott et al. (1965) applied the 'bone-in-pen" test to individual pairs of puppies in order to discern whether dominance relationships occurred. An observer recorded the behaviour of both puppies including the occurrence of growls, barks, attacks, and other forms of agonistic behaviour. Although all degrees of dominance appeared in the interactions (various postures associated with each role), they found little evidence of a consistent dominance hierarchy and concluded that the capacity to establish stable dominance relationships is a product of inherited aggressive tendencies and that an individual's likelihood of becoming socially dominant is strongly dependent on previous experience with conspecifics.

Scott et al. (1965) also noted breed differences in aggression, with some breeds showing little or no aggression at any age (Beagles and Cocker Spaniels), and that large differences in the capacity to form dominance relationships are a reflection of the breeds differences in aggressive tendencies. They discussed the effects of domestication on an individual's motivation (in this case for bone acquisition), observing that hunting breeds 
were strongly motivated by food but differed greatly in aggressiveness, which resulted in some breeds competing more for possession of the bone than others. In regards to the 'bone-in-pen' test, Serpell (1995) noted that it ignored the possible effects of temporary motivational differences between individuals at the time of testing (hungry, bored, tired...), and the influence of temperament, such as persistence or confidence, which may or may not be related to social dominance.

The results of the 'bone-in-pen' test suggest that domestication has had a marked effect on the expression of dominance-related aggressiveness in dogs and as a result, hierarchy formation. Research on the social behaviour of the dog conducted by Bradshaw et al. (2009) demonstrated considerable instability in the relationships between individuals; far more than might be expected to underlie a straightforward progression towards a stable hierarchy, this in accordance with the findings of Scott et al. (Serpell, 1995).

\subsection{Behavioural and Morphological Changes From Domestication in the Dog}

The 'bone-in-pen' test led to several noteworthy conclusions in regards to the social behaviour of the dog. First, breed differences had a marked effect on motivation (Scott et al., 1965; Hart et al., 1985; Serpell, 1995). For example, Shetland sheepdogs are motivated to defend territory but do not exhibit the same level of motivation for food rewards. In contrast, Basenjis appear to be motivated for food rewards and less so in regards to territory defense (Scott et al., 1965). Furthermore, motivation also differs by individual and context (Serpell, 1995). As we can see, the outcome of a contest between two dogs is strongly linked to the motivation of each individual and a dog perceived as 'dominant' in a one context may act 'submissive' in another, and vice-versa. 
Second, the 'bone-in-pen' test demonstrated that breeds differ greatly in their aggressive tendencies (Scott et al., 1965). For example, Beagles and Cocker Spaniels showed little or no aggression at any time during the test. In contrast, hunting breeds which were highly motivated by food, differed in aggressiveness which resulted in some breeds competing more for possession of the bone than others. Bekoff (1974) argued that the beagle, having been artificially bred for purposes of pack hunting, increased sociability and decreased agonistic behaviour would be important traits to maintain. By the same token, terriers, bred for the purpose of the solitary hunting of small game, are argued to be more aggressive and less social (Coppinger et al., 2001).

Lastly, in regards to aggression, it is likely to be less costly in dogs than in the wolves because of human intervention before, during and after conflicts. Therefore the cost of failing to display submissive behaviour is reduced, allowing for its elimination from the behavioural repertoire (Goodwin et al., 1997).

\subsection{Behavioural Variation: The Predatory Sequence in the Domestic Dog}

It has been noted that artificial selection and domestication have altered and constrained the dog's predatory motor sequence (Coppinger et. al., 1987). The predatory motor sequence in wolves consists of: orient which is to locate prey; eye, which is to stare at and maintain eye gaze on prey; stalk, which is to slowly approach prey in a crouched or semi-crouched position; chase, which is to run towards prey; grab-bite; which is to make first contact with prey in an attempt to slow or take down prey; kill-bite and dissect, which is to deliver a bite to the throat of prey in order to kill it; each of which is essential for the successful hunting of prey (Coppinger et al., 2001). People breeding dogs for specific jobs have altered the predatory behaviour such that not all breeds of dog have a 
complete predatory sequence. For example, there exist two types of sheep dog - herding and guarding - each of which is behaviourally distinct. Both are bred separately in similar environments. Adult herding dogs do not exhibit social play approach behaviour towards sheep while guarding dogs do. Also, herding dogs routinely stalk the sheep, but do not attack and kill them. Interestingly, guarding dogs would not hunt, let alone kill and eat live or anesthetized chickens, while wolves and herding dogs did (Burhardt, 2005). It is thought that livestock-guarding dogs have been selected for pre-predatory behaviour and, as a result, have lost the predatory sequence completely (Coppinger et. al., 1987; Burghardt, 2005). This makes sense when we consider that livestock guarding dogs are bred, as their name suggests, for the guarding of livestock. Therefore it is imperative that they do not show aspects of the predatory sequence that might result in the injury or death of the animals they are in charge of guarding.

Another example of an altered predatory motor pattern is the increased intensity of 'eyeing' in Collies (Miklosi, 2007). Eyeing occurs at the beginning of the predatory sequence in wolves after the orientation towards prey (Miklosi, 2007). Collies are specifically bred to orient towards and 'eye' livestock. However, the remainder of the predatory sequence has been extinguished.

This all suggests that the dog is a 'mosaic' of the ancestral wolf pattern and that, depending on the breed and context, individuals may only display a restricted subset of the wolf ethogram (Miklosi, 2007). This has implications for the expression of dominant and submissive behaviour. 


\subsection{Effects of Domestication on the Dog: Paedomorphism and Signal}

\section{Ambiguity}

Many of the structural modifications of the domestic dog can be explained by changes in the rate of development during domestication (Goodwin et al., 1997; Burghardt, 2005). Frank et al. (1982) noted that mutations in the regulatory genes of the dog have led to the retention of juvenile features, including the threshold for aggression, into adulthood. Further, dogs showing extreme paedomorphism often exhibit a reduction in overall body size and retain a juvenile head to body ratio (Goodwin et al., 1997). The domestic dog has undergone a tremendous transformation in the direction of docility and affectionate dependency leading to the conclusion that dogs never mature fully (Lindsay, 2000). Paedomorphism has affected the development of the brain and nervous system as well as the skeleton, and more paedomorphic dogs display the most infantile wolf behaviour (Goodwin et al., 1997).

Domestication and artificial selection in the dog have led to differential rates of development resulting in the disintegration of the wolf's well-defined and predictable dominance displays into an assortment of fragmented behaviours (Lindsay, 2000; Coppinger et al., 2001). This disintegration of dominance displays has freed the domestic dog's behavioural actions from their original motivational context (Miklosi, 2007). The clear and unambiguous signals of the wolf have been replaced with a collection of generalized signals that promote social promiscuity through exaggerated care-seeking behaviours and various 'active' and 'passive' submission fragments (Lindsay, 2000). Submissive displays have lost much of their adaptive function, including their behavioural integrity and social significance (Frank et al., 1982). 


\subsection{A Note on Behavioural Similarities Between the Domestic Dog and the Wolf}

Before the discussion moves to morphological changes due to domestication in the dog, it should be noted that although the behaviour of the dog has changed substantially from the ancestral pattern of the wolf, it is not the case that dogs have completely lost the ability to display their internal state, whether confident or timid in any given context, through the use of behavioural and postural displays inherited from the wolf. For dogs and wolves alike, posture can announce aggressive intent or shrinking modesty. To simply stand erect at full height, with head and ears up is to announce readiness to engage. To exaggerate the whole effect, a dog might not just stand up, but also over another dog, with its head and paws on its back (Horowitz, 2010). As in wolves, the opposite body posture: crouching with head down, ears down, and tail tucked away is a clear sign of timidity and a lack of confidence (Horowitz, 2010). Where the dog differs substantially from the wolf is in the context within which specific behaviours and postures are used. During agonistic encounters a timid dog may roll over onto its back, a behaviour that when demonstrated by wolves has been taken to be a clear sign of submission. However, Bradshaw et al. (2009) researched differences in competitive behaviour in the domestic dog by recording the total number of "confident" behaviours (e.g. growls, inhibited bite, stand over, mount, stare at, chase, bark at) and "submissive" (e.g. crouch, avoid, displacement, lick/yawn, run away). He did not find evidence of a clear-cut dominance hierarchy. Thus, if there does not exist evidence for the formation of dominance based relationships in the dog, then it is possible that behaviours such as rolling over are being utilized for functions other than to signal submission. 


\subsection{Morphological Differences Between the Domestic Dog and the Wolf}

Goodwin et al. (1997) found that the further the dog has diverged from the appearance of the wolf, the more likely it is that lupine behaviour has been lost. Only a few breeds are morphologically sufficiently similar to be able to signal to the full extent as wolves. Huskies, for example, have maintained a resemblance to wolves and are capable of displaying many of the signals seen in wolves (Lorenz, 1954; Bradshaw, 2009). Unfortunately, humans, in breeding dogs to have particular looks that they find agreeable, have limited or removed their ability to communicate effectively (Horowitz, 2010). The next section will briefly outline the anatomy of the dog utilized in social communication and discuss if applicable the effects of domestication.

\section{Head}

Morphology permitting, dogs are able to retract the commissures of the lips the same as wolves. The mouth can sweep from closed to open and relaxed, to open with lips raised, snout wrinkled and teeth bared (Horowitz, 2010). When the jaws are closed and the commissures of the lips are pulled back it is described as a 'submissive grin'. As the mouth is opened, the arousal increases; and if the teeth are exposed, the look becomes aggressive (Lorenz, 1954; Horowitz, 2010). Coming full circle, a wide-open mouth, with teeth mostly covered - a yawn - is not a sign of boredom, and may be indicative of anxiety, timidity, or stress, and is used by dogs to calm themselves or others (Horowitz, 2010). To further complicate things, some breeds of dogs are brachycephalic and have faces that are 'pushed in'. Brachycephaly prevents a dog from activating its face muscles and therefore is not able to convey as much information with its face. 
The ears of the dog can be erect (much like the wolf) or extremely long and draped as in the Basset Hound. Morphology permitting, dogs with erect ears are capable of the same range of movement as seen in the wolf.

\section{Fur}

The fur of the domestic dog is substantially different than the fur of the wolf. Unlike wolves, the fur of the dog has lost much of its communicative value. Different breeds of dog have fur that is: long, short, curly, straight, monochromatic, or multichromatic. Not only does the fur vary from breed to breed but also substantially between individuals. Further complicating the situation, humans often shave their dogs and as a result, many dogs are not able to raise their hackles with pique, which has obvious implication for dogdog interactions (Horowitz, 2009).

\section{Tail}

Like wolves, body posture and tail carriage are accurate indicators of a dog's changing mood and intention (Lindsay, 2000). An erect tail exposes the anal region allowing a bold dog to air his odour signature. In regards to so-called 'submissive' displays or timidity, dogs with limited tail mobility are not able to lower or tuck their tails between their legs.

During head-to-tail olfactory inspection, the interaction can be terminated by either dog and it is common for both dogs to attempt to avoid being sniffed by tucking their tails. This is unlike dominant wolves who present their anogenital region for inspection. In this respect dogs act like subordinates wolves (Serpell, 1995; Bradshaw et al., 2009).

The tail of the domestic dog has been drastically altered by artificial selection. Wolves have highly expressive tails that they are able to hold in a variety of ways so as to 
communicate various internal states (see prior discussion). In contrast, most dogs carry their tails in either a tightly curled or sickle-like shape, tail shapes that wolves never or rarely exhibit (Lindsay, 2000; Horowitz, 2010; Miklosi, 2007).

Finally, dogs vary dramatically in size from breed to breed and individual to individual (Fox, 1970; Horowitz, 2010; Bradshaw, 2011). It is not unheard of for a teacup poodle, weighing a mere three or four pounds, to coexist peacably with a Great Dane, weighing two hundred pounds. This raises the question of what the consequences of the behavioural and morphological segregation of the domestic dog from wolves are in regards to the mediation of social interactions? As has been discussed, wolves rely on a variety of behaviours and postures in order to mediate social encounters. These behaviours and postures manifest themselves as 'dominance' and 'submission' and form the rigid dominance hierarchy characteristic of wolves. It would be expected that if dogs interacted hierarchically then the inability to clearly signal 'submission' when faced with aggression would lead to an escalation of aggression. Numerous studies have concluded that this is not the case, and a possible explanation is that dogs are not relying on rigid displays of 'dominance' and 'submission' to regulate social interactions (Bradshaw et al., 2009). A possible explanation is that unlike wolves, visual communication may play a lesser role because dogs of different breeds have incompatible visual signals due to the modification of their behaviour and morphology (Serpell, 1995; Bradshaw et al., 2009). Studies have confirmed that in permanent groups of dogs, wolf-typical signaling seems to be rare (Serpell, 1995; Bradshaw et al., 2009). Furthermore not only is the rate of signaling different between breeds but research looking at the range of signals used by ten physically dissimilar breeds identified communicatory difficulty (Horowitz, 2010). For example, the number of ancestral dominant and submissive behaviour patterns used 
during signaling ranged from two (Cavalier King Charles spaniels) to fifteen (Siberian husky) (Goodwin et al., 1997; Horowitz, 2010). These findings correlated positively with the degree to which the breed physically resembled the wolf, as assessed by a panel of 14 dog behaviour counselors.

Now that it has been established that the domestic dog does not behave in a typically wolf-like fashion, the discussion will move to how the domestic dog overcomes the aforementioned differences in behaviour and morphology when interacting with conspecifics. The discussion will focus specifically on rough-and-tumble play, an activity in which dogs frequently engage, and how they manage to cooperate and compete while avoiding the onset of aggression.

\subsection{Play in the Domestic Dog}

Despite the evidence demonstrating a lack of wolf-typical behaviour in the domestic dog, there remains a strong inclination to interpret dog behaviour using ethograms derived from studies on wolves. For example, it has been stated that in the dog, the critical period for the formation of intraspecific and interspecific social relations, including the establishment of dominance based relationships, is between three and seven weeks (Bekoff, 1974). Rough-and-tumble play uses salient aspects of these relationships derived from aggressive interactions, such as 'submission' in the form of rolling over into a supine position (Bekoff, 1974). More recently, Bauer et al., (2007) predicted that any variation in play style would reflect salient aspects of the established social system, including dominance relationships. They concluded that although the rules governing social relationships in the dog are relaxed, they still affect the outcomes by regulating the use of 
varying tactics, such as role reversals and self-handicapping (Bauer et al., 2007). Despite the authors concluding that it is difficult to distinguish rank effects on behaviour with the effects of size and age, their paper is still heavily laden with the terms 'dominant' and 'submissive', and the subjects' behaviour is still interpreted within the frame of a dominance relationship.

A major issue with applying wolf behaviour to the social interactions of the domestic dog is that it ignores findings that deny the existence of hierarchical relationships in the dog. Although Bekoff (1974) concluded that submissive actions are used during play in the domestic dog, he also noted that no discernible dominance relationships were found. This is in accordance with Scott et al. (1965), who found no discernible dominance relationships when considering competitive interactions in the dog. Furthermore, current research conducted by Bradshaw et al. (2009) concluded that dominance based relationships do not exist in the dog. Furthermore, Bradshaw et al. (2009) notes that even if dominance were to exist in the dog, it has erroneously been used to describe a supposed trait of individual dogs rather than being applied correctly as a property of a relationship. When used correctly to describe a relationship, it tends to be misapplied as a motivation for the interaction, rather than a quality of that relationship (Bradshaw et al., 2009).

The next section will consider how dogs facilitate and maintain play through the use of tactics believed to be derived from dominance-based relationships. Such tactics include role reversals and self-handicapping. However, in order to understand how play is regulated, an overview of what play in the dog entails will be provided 


\subsection{What is play in the domestic dog?}

Although play in the domestic dog is readily identified, researchers have had a difficult time defining it objectively. Play is often characterized by what it is not: it is not aggression, predatory, or copulatory behaviour (Goodwin et al., 1997). A widely utilized definition of canid play is as follows: (i) the use of actions from various contexts which are incorporated into labile and unpredictable temporal sequences, including inhibited biting coupled with side to side head shaking in the absence of prey or true aggression; predation; or reproduction, (ii) the play bout is typically preceded by a metacommunicative signal such as a play bow, whereby the dog signals it's intent to play by lowering its forequarters while simultaneously raising its hindquarters (iii) certain actions may be repeated and performed in an exaggerated manner such as the way in which a dog leaps towards and away from a prospective play partner; (iv) the activity is voluntary and appears to be pleasant to both individual (Bekoff, 1974). Canid play also includes behaviours such as chasing and play-fighting, inhibited biting, and mounting behaviour derived from copulation (Bekoff, 1974).

The next section will provide an overview of the current understanding of how dogs maintain and facilitate play while at the same time avoiding the onset of aggression.

\subsection{The Facilitation and Maintenance of Play}

A main concern for those studying play has been the question of how a playful mood is established and maintained between interacting animals, particularly when it contains elements of aggression (Bekoff, 1974; Pellis et al., 1996; Bauer et al., 2007). During rough-and-tumble play, individuals bite, push, and pin their opponents (Symons 1978; Fagen, 1981; Pellis et al., 1987; McLeod et al., 1997; Biben, 1998). Rough-and-tumble 
play combines elements of competition and cooperation, and requires individuals to be in close association with one another, engaging in attack and defence maneuvers (Aldis, 1975; Symons, 1978; Fagen, 1981; Bekoff, 1995; Bauer et al., 2007), and yet such vigorous play rarely results in true aggression (Power, 2000; Bauer et al., 2007). Interactants cooperate in order to maintain the playful atmosphere, and compete to keep the interaction interesting for both individuals. Maintaining a playful atmosphere is particularly challenging when the partners possess dissimilar morphology and have differing behavioural repertoires (Altmann, 1962; Biben, 1998; Bauer et al., 2007).

In the canids, maintenance of a play mood appears to be accomplished by the rapid and efficient exchange of subtle and fleeting metacommunicative signals between interactants, such as the aforementioned 'play bow' (Bekoff, 1974). Researchers have discerned two primary means by which canids facilitate and maintain play; role reversals and self-handicapping, each of which serves to reduce asymmetries between interacting animals and foster the reciprocity needed for play to occur (Bekoff, 1974; Burghardt, 2005; Ward et al., 2008).

\section{Role Reversals}

Role reversals occur when a dominant individual allows itself to be dominated by a subordinate animal within the confines of play (Bekoff, 1974). Role reversals facilitate and maintain play by affording a disadvantaged individual the chance to gain the upper hand. For example, a dominant individual may perform an action during play that would not normally occur during real aggression, such as rolling onto its back, an action characteristic of subordinate animals during aggression (Allen et al., 2002; Bauer et al., 2007). Should a dominant individual suddenly switch roles at any point during play by 
becoming overly aggressive, it would be playing in an unfair manner and there is a chance that the interaction may escalate into true aggression (Dugatkin et al., 2003).

The assumption that each individual belongs to, and functions within, a dominance relationship is inherent in the consideration of role reversals. In order for traditional roles to be reversed, it must follow that one animal be dominant, and that the other be submissive, outside of play. Ward et al. (2008) analysed role reversals during play in the domestic dog by first determining the established dominance relationships. They assessed dominance relationships based on interactions in non-play contexts using descriptions of postural indicators of dominance in wolves provided by Schenkel (1967); Mech, (1970); and Abrantes, (2005). Ward et al. (2008) labeled dogs that consistently expressed dominant, upright postures (with head and tail raised) 'established dominants', and dogs that consistently lowered their bodies (with head and tail lowered and ears pressed flat) 'established subordinates'.

The problem with this interpretation of dog behaviour is that, as it has been discussed, it does not appear that dogs form dominance relationships. As well, Ward et al. (2008) Concluded that normal social roles are generally suspended during play. If research suggests that dominance relationships do not develop in the domestic dog, and if they are found, are suspended during play, then behaviours such as rolling over must serve another function during play other than submission.

\section{Self-Handicapping}

Self-handicapping occurs when an individual performs a behaviour pattern that might compromise itself to the advantage of a previously disadvantaged partner. For example, an individual might not bite its partner as hard as it can, or it may refrain from vigorous 
play (Bekoff, 1974). Watson et al. (1996) found that red-neck wallabies adjust their style of play according to the age of their partner. When the partner was younger, the older individual adopted a defensive stance characterized by a flat-footed posture and pawing, rather than sparring. The older animal was also more tolerant of the younger and took the initiative in prolonging interactions (Watson et al., 1996).

In the dog, self-handicapping is a means by which larger individuals are able to facilitate and maintain play with a smaller dog (Burghardt, 2005). Similar to rolereversals, it is assumed that self-handicapping occurs within the confines of a dominance relationship. Dugatkin et al. (2003) state that self-handicapping occurs when a dominant individual allows a subordinate to act in ways that it could easily prevent. For example, during play a larger dog may roll onto its back and let a smaller dog pin it to the ground.

Unlike role reversals, where dominant and submissive roles are intrinsic, it is possible for self-handicapping to occur without the existence of a dominance relationship. All that is required is for the individual with the upper hand, whether it be in size or age, to relinquish its current advantage.

Lastly, Goodwin et al. (1997) found that very few signals used to mediate social tension were associated with submission in wolves. Specifically, they found that rolling over as passive submission was an infrequent occurrence. Goodwin et al. (1997) concluded that the high frequency of signals used in playful contexts supports the idea that domestication has substantially altered the behaviour of the domestic dog. 


\section{Chapter 3: Methods}

\subsection{Data set 1 . Staged play with a target dog}

\subsubsection{Subjects}

I paired a single medium-sized female dog with 33 play partners of differing sizes and breeds (see Table 1). This approach enabled the selection of test subjects that were bigger, smaller and the same size as the standardized play partner. Although this raises unavoidable issues of pseudoreplication, I did so for three reasons. First, I wished to ensure that all play partners were unacquainted with each other so that recorded rollovers could not be ascribed to any prior establishment of dominance. Second, and following this, by using a known dog with a placid temperament, I wanted to allow for the possibility that being paired with an unknown dog would elicit behaviours associated with dominance and subordination, while minimizing the risk of agonistic escalation. Third, having a standard target dog for each of the subjects allowed me to assess the effects of relative size differences while reducing any effect of other individual differences in the dyads.

I used opportunistic sampling of owners at a pet store in Lethbridge, Alberta to recruit subjects. I asked the owner(s) if their dog was well-socialized (i.e. did it have experience of daycare centres or playgroups) and whether they could recall any instances in which the dog had been involved in aggression. Dogs with a history of overt fighting were excluded from the study. I obtained body weight and height data from the owners. All procedures were approved. 
Table 1. Identity and characteristics of dogs used in the first study

\begin{tabular}{|c|c|c|c|c|c|}
\hline NAME & BREED & WEIGHT LB & HEIGHT IN & LENGTH IN & Total Play (SEC) \\
\hline Jetta & Labrador Retriever Cross & 41 & 23 & 25 & 0 \\
\hline Cricket & Labrador Retriever Cross & 28 & 17 & 21 & 0 \\
\hline Reese & Pug & 20 & 12 & 12 & 571 \\
\hline Duke & Rhodesian Ridgeback & 90 & 28 & 26 & 83 \\
\hline Finn & Bull Terrier & 58 & 20 & 19 & 1433 \\
\hline Daisy & Great Pyrenees & 94 & 29 & 28 & 0 \\
\hline Lulu & Pug & 26 & 12 & 13 & 277 \\
\hline Griffin & Labradoodle & 55 & 20 & 25 & 269 \\
\hline Lexi & German Shepherd & 58 & 26 & 27 & 2492 \\
\hline Sheba & Coonhound & 68 & 26 & 26 & 0 \\
\hline Nacho & Miniature Pinscher & 10 & 13 & 10 & 269 \\
\hline Tucker & Corgi Cross & 46 & 14 & 23 & 583 \\
\hline Sadie & German Shepherd Cross & 90 & 25 & 29 & 541 \\
\hline Rupert & Boston Terrier Cross & 21 & 14 & 12 & 974 \\
\hline Dixon & Jack Russell Cross & 14 & 12 & 11 & 1214 \\
\hline Keisha & Great Dane & 160 & 32 & 34 & 164 \\
\hline Zoe & Boxer & 70 & 22 & 21 & 1203 \\
\hline Lucy & Chocolate Lab & 60 & 23 & 20 & 0 \\
\hline Oliver & Golden Retriever & 86 & 27 & 25 & 0 \\
\hline Loki & Chow Cross & 76 & 22 & 24 & 991 \\
\hline Odin & Husky Cross & 88 & 24 & 29 & 2181 \\
\hline Bailey & Golden Retriever & 65 & 23 & 26 & 0 \\
\hline Bonnie & Red Nosed Pitbull & 54 & 20 & 21 & 809 \\
\hline Diesel & Border Collie Cross & 48 & 19 & 19 & 2518 \\
\hline Chino & Chow Cross & 45 & 19 & 26 & 0 \\
\hline Dewey & Great Pyrenees Cross & 65 & 24 & 25 & 0 \\
\hline Bart & Welsh Terrier & 24 & 16 & 15 & 57 \\
\hline Gibson & Black Labrador Retriever & 72 & 24 & 23 & 87 \\
\hline Seamus & Airedale Terrier & 52 & 25 & 21 & 1335 \\
\hline Jaxson & Boxer & 72 & 23 & 20 & 1240 \\
\hline Izzie & Basset Hound & 65 & 15 & 23 & 65 \\
\hline Boomer & Coonhound Cross & 55 & NA & NA & 35 \\
\hline Jethro & Collie Cross & 25 & NA & NA & 0 \\
\hline
\end{tabular}




\subsubsection{Procedure}

Play sessions took place in an indoor laboratory containing a cordoned-off play arena measuring $5.5 \mathrm{~m} \times 3.5 \mathrm{~m}$. This area included a door that opened into a small room in which the target dog was placed before the session began. Each session involved only the target dog and a single partner. On arrival, owners brought their dogs into the laboratory, placed them in the arena and remained with them until they had settled in. Once the dogs were relaxed, the owners left the laboratory and the target dog was released from the holding room. Two researchers remained to record the session and to manage the dogs. A pilot study indicated that dyads that were left alone in the arena tended to focus their attention on the researchers and so did not interact with each other. Accordingly, to overcome this, we spoke to the dogs or petted them until they either started playing or had ignored each other for five minutes. Data collection took place between 6pm and 8pm, from June to August 2011.

I used a Samsung SD camcorder to document sessions and began filming once the dogs engaged with each other, either by coming face-to-face and making prolonged eye contact or when one of the dogs sniffed the other. Filming was ceased if the dogs had not interacted with each other for more than five consecutive minutes.

\subsection{Data set 2. YouTube videos of playing dogs}

To obtain video footage of unique pairs of playing dogs, thereby addressing the pseudoreplication inherent in Data set 1, I searched YouTube, using the keywords 'dogs' and 'playing', and selected 20 videos in which the beginning and end of play bouts were clearly discernible. I selected 10 videos in which partners were judged to be of approximately the same size and 10 in which the two dogs were judged to differ in size. 


\subsection{Data extraction}

I used the Free Video to JPEG Converter (v. 5.0.6. build 221) software to reconfigure the video as individual frames $(25 \mathrm{fps})$. When viewing the recorded sessions, I used the ethograms provided by Bekoff $(1972,1974)$, Horowitz (2009) and Ward et al. (2008). Playful interactions varied from rough-and-tumble play to the chasing of one dog by the other. In the latter case, we used the descriptions of canine body language by Abrantes (2005) and Handelman (2012) to distinguish between play and avoidance behaviour.

The converted footage allowed quantitative estimates to be made of the number of rollovers performed by each subject, the frequency with which rollovers occurred, the duration of the play bout, as well as the duration of the supine phase of the rollover, in which the animal was on its back with all four feet off the substrate. Moreover, the videotaped material also allowed Eshkol-Wachman Movement Notation (Golani, 1976) to be used for detailed qualitative analysis of the contexts in which rollovers occurred.

\subsection{Data analysis}

\subsubsection{Qualitative analyses}

Eschol-Wachman movement notation (EWMN) is a globographic system, designed to express relations and changes of relation between parts of the body, with the body (i.e., body and limb segments) treated as a system of articulated axes (Golani, 1976). An important feature of EWMN is that the same movements can be notated in several polar coordinate systems. The coordinates of each system are determined with reference to the environment, to the midline axis of the subject's body, and to the next proximal or distal 
limb or body segment. Its primary value in the study of social interactions is that the movement by one animal can be described as relative to the body of the other animal (Moran et al., 1981; and see Appendix A in Pellis et al., 2013 for a detailed outline of how the system is used to record the behavior of two interacting animals). By transforming the description of the same behaviour from one coordinate system to the next, invariance in the behaviour may emerge in some coordinates but not others (Golani, 1976).

I used EWMN to describe 20 rollovers occurring in playful interactions containing rollovers from data set 1 to identify when and how rollovers occurred. Then, EWMN was used to describe 20 rollovers in play fights from data set 2 which were also notated as an independent evaluation of whether the contexts identified for the use of rollovers were common to a wider range of dogs. The categories of rollovers identified in this way were then subjected to quantitative analyses using the fuller data sets of available rollovers.

As the most subjective phase of the analysis was the EWMN descriptions, a procedure was implemented to ensure their objectivity. The principal observer (KN) produced all the EWMN scores. Twelve of the notated scores were randomly selected and read by another experienced researcher (S. Pellis), who had not previously watched the video sequences. This reader then provided a verbal and written description of the sequences and these were compared to the actual videotaped behaviour of the dogs. In each case, the naïve reader recreated the actual movements performed to confirm that the EWMN scores were an accurate descriptive representation of the behaviour.

\subsubsection{Quantitative analyses}

For the analysis of data set 1 (play with a target dog), I analyzed only play partner data. As I found a strong positive correlation between the height and weight of the target 
dog and those partner $\operatorname{dogs}(\mathrm{N}=27)$ that did play $(\mathrm{r}=0.85, \mathrm{~N}=27, \mathrm{P}<0.001)$, I confine my presented analyses to height. Using weight did not affect the outcomes. I used logistic regression to determine the effect of body size and play bout duration on the probability that rollovers would occur during a bout. In the analysis of the duration of the supine phase of the rollover (hereafter 'rollover duration'), where subjects contributed more than one datum to analysis, I ran generalized linear mixed models (GLMM) under restricted maximum likelihood estimation, with rollover duration as the dependent variable and subject identity as the random effect. I conducted all statistical tests using Stata 13 (Statacorp 2013) or JMP 10 (SAS Institute 2012). Tests were two-tailed, with alpha = 0.05. Again, data from the two data sets were analyzed separately so as to determine whether both converged on the same patterns. 


\section{Results}

\subsection{Qualitative analyses of rollovers}

From the 40 sequences notated using EWMN, four distinct categories of rolling over were discernible. Given that few people are able to read EWMN scores, the types of rollovers are described in written form with photographs of sequences illustrating the main types. While several contexts were identified in which rolling over occurred, in none of the 40 interactions subjected to EWMN analysis, did any dog roll over in a manner that was consistent with submission. That is, no dog rolled over in response to an approach or aggressive action by the partner and did not remain passive on its back. A quantitative evaluation of all instances of rolling over was conducted to ascertain whether such submissive rollovers were ever present (see section 3.3).

\subsubsection{Offensive Rollovers}

During rough and tumble play, dogs compete to make contact with, and bite the nape and neck region of their partner (Figure 1). To gain such access, the attacking dog may lunge forward and roll over onto its back, raising the head with open mouth, biting at the throat as the distance is narrowed. The roll occurs around the longitudinal axis and is coupled with a lateral component if the approach is from the side. 

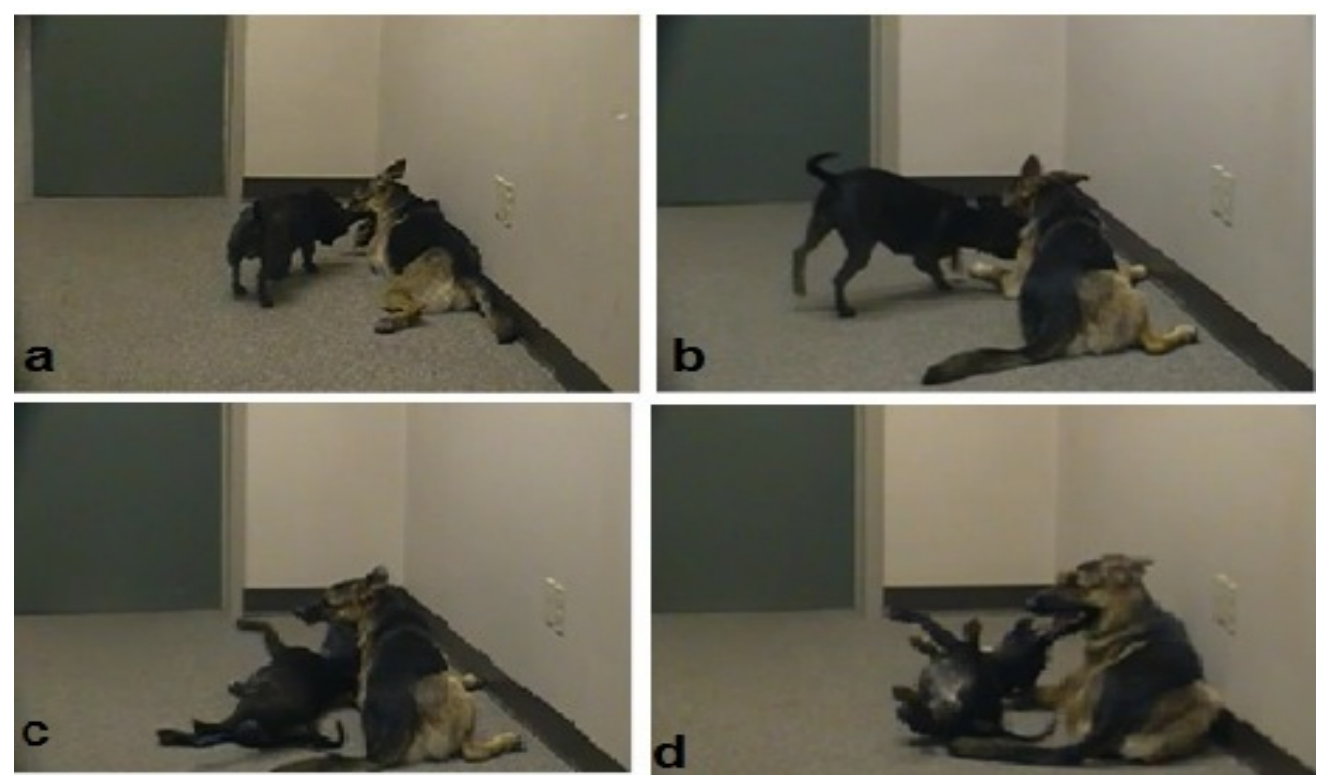

Figure 1. Photographs illustrate a sequence involving an offensive rollover. The target dog (TD) approaches the anterior head and neck of the German shepherd with her head lowered and her mouth open (a) then rotates around her longitudinal axis with her mouth oriented towards her partner's chin (b). Once lying on her side, TD lunges up and bites her partner's cheek (c). The partner lifts her head and leans back, moving her face out of TD's grasp, but then TD lunges again with her mouth open (d).

\subsubsection{Defensive Rollovers}

When one partner attempts to make contact with the nape and neck region of their partner, the recipient may avoid such contact by rotating their head and neck, thus moving the nape away. If such rotation is insufficient to prevent contact, either it is coupled with the lowering of the forequarters or the rotation of the upper and lower torso around the longitudinal axis until the dog is lying on its side or back. From this position, the defender not only moves its nape out of reach but it is also in a position to block any further attack with its forepaws and its own open-mouth lunges at its partner 

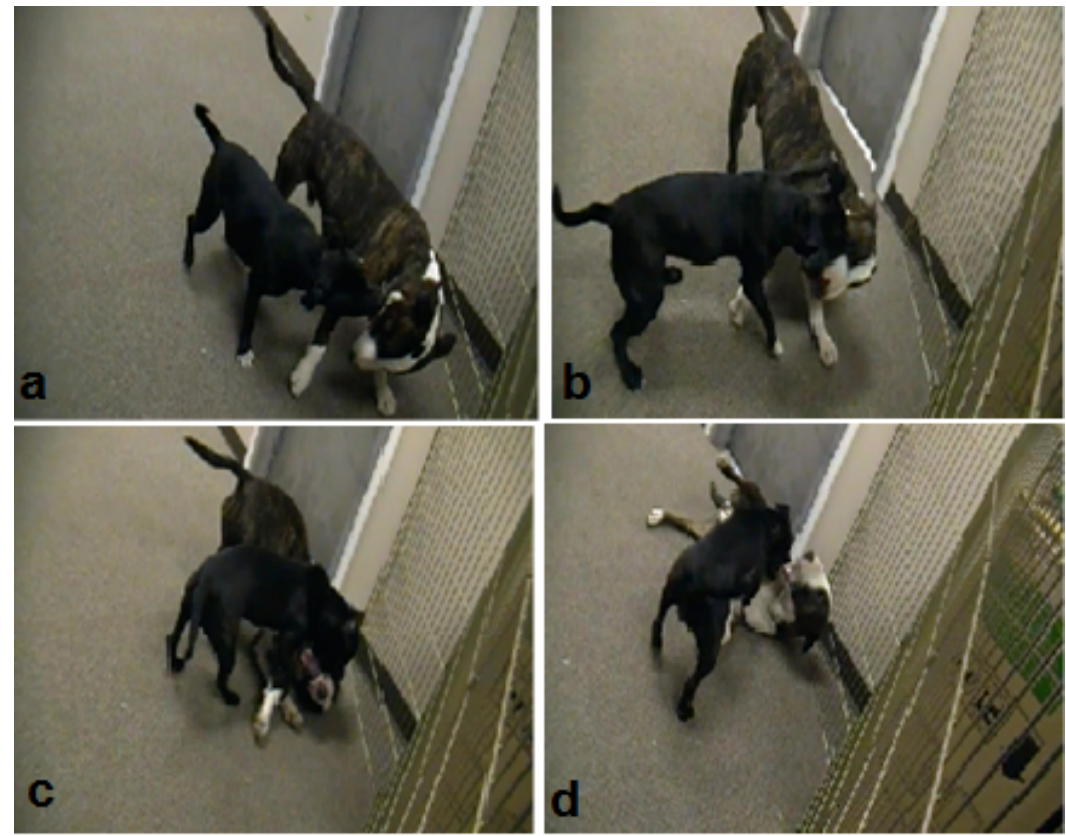

Figure 2. Photographs illustrate a sequence involving a defensive rollover. TD approaches and makes contact with the right side of the bull terrier's neck (a). The bull terrier begins to rollover by rotating his head and directing his mouth towards TD's mouth (b and c). Once fully on his back, the bull terrier counters TD's advances by opening his mouth and moving it to block TD's open mouth lunges (d).

\subsubsection{Solicitation Rollovers}

Solicitation rollovers occur in the absence of any clear offensive or defensive movements towards or away from the neck. The performer is oriented towards the partner, gazing in that general direction, then will roll around the longitudinal axis until lying on its back in close proximity to the other dog. That these types of rollovers are associated with attempts to solicit play is suggested by the frequent occurrence of play bows before the roll. If the partner does not engage in play, following a rollover the performer 
regains a standing position and may attempt another play bow or solicitation roll, or may cease interacting all together.

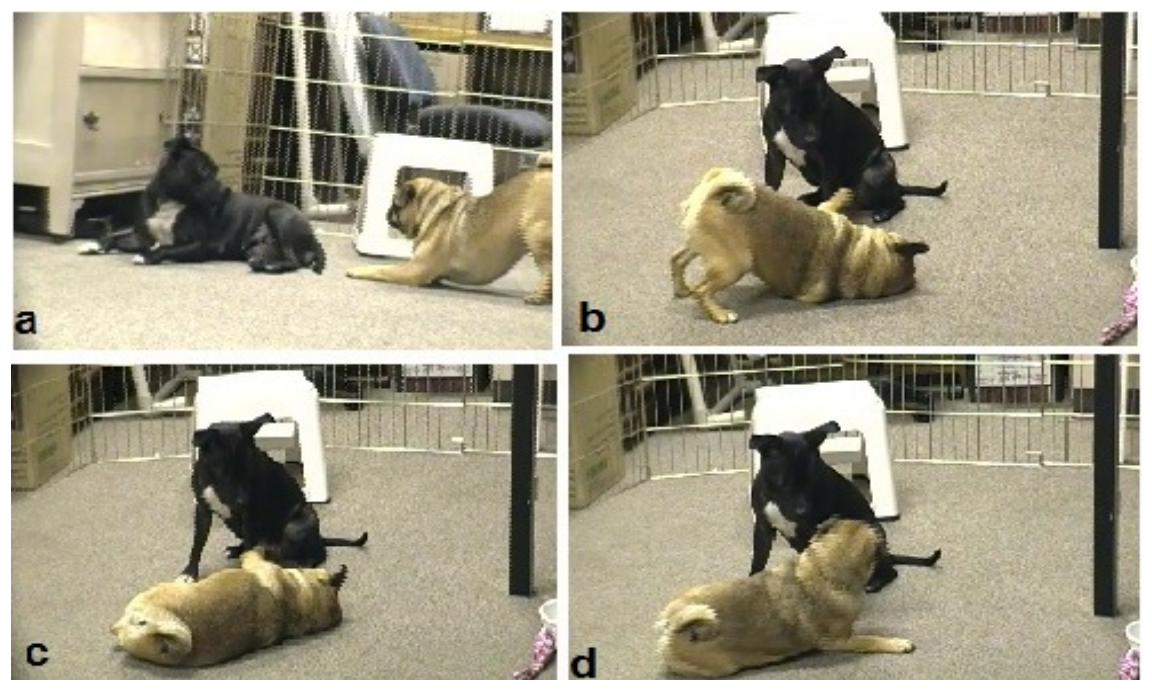

Figure 3. Photographs illustrate a sequence involving a rollover that is used to solicit play from a partner. The pug on the left (a) approaches TD and performs a play bow. TD moves away without responding playfully, and the pug orients laterally in front of her and rolls over onto his side ( $b$ and $c)$. Although TD looks down at him, she does not initiate play. The pug sits and gently, with his left paw, paws toward TD's face $(d)$.

\subsubsection{Other}

The other instances whereby rolling over occurred were during periods of rest in which the individual ceased playing and moved away from their partner. These rollovers had no discernible social context and are likely to be non-social. 


\subsection{Quantitative analyses of rollovers}

\subsubsection{Date set 1: Target dog}

\subsubsection{Aggression and the occurrence of play}

I recorded no aggressive behaviour from the target dog and no rollovers prior to the initiation of play by any partner dog. Ten of the 33 partners did not engage in play. Three of these growled at the target dog when introduced to it, whereas only two dogs that subsequently played did (Fisher Exact Test, $\mathrm{P}=0.053)$. The clearest indicator that play would ensue was tail wagging by the partner dog. Three of the 10 dogs that did not play wagged its tail while 17 of the 23 active play partners did so (Fisher Exact Test, $\mathrm{P}=0.026$ ). Among the dogs that did play, the mean play bout length was $843.1 \mathrm{~s}( \pm 770.7 \mathrm{SD})$.

\subsubsection{The occurrence of rollovers during play}

Nine of the 23 play partners rolled over during the play bout. To determine what factors would predict whether a rollover would occur, I ran a logistic regression with the height of the play partner relative to that of the target dog (partner height/target height) and play bout duration (s) as independent predictors (Table 2). The results indicate that play bout duration, but not relative height, was positively associated with the likelihood that a play bout would elicit at least one rollover (Figure 4). For those nine animals that did rollover during play, the correlation of relative 
height against rollover frequency, with play bout duration controlled for, was $\mathrm{r}=0.56(\mathrm{~N}=9, \mathrm{P}=0.11)$.

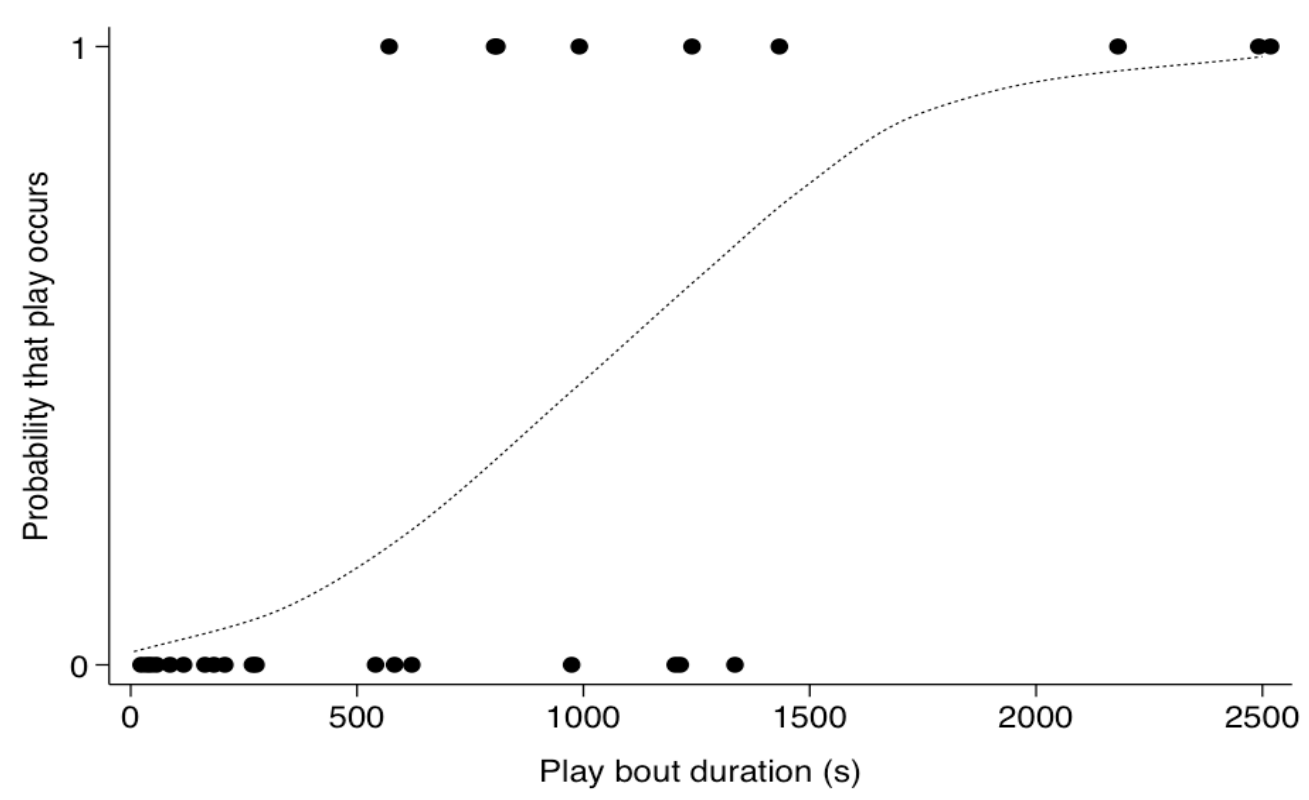

Figure 4. The relationship between the duration of the play bout and the likelihood that it will contain a rollover is shown. Circles identify actual play bouts, while the line indicates the transitional probability.

\subsubsection{Duration of the supine phase of the rollover}

We assessed the effect of relative height on the duration of the supine phase of the rollover by the nine play partners that did roll over during play ( $\mathrm{N}=87$ instances). To control for repeated measures, we entered partner identity as a random effect in a GLMM. The results indicate that the effect of relative height was significant (Table 3), with larger partners sustaining the supine posture for longer. 
Table 3. The relationship between the height of play partners relative to the target dog and the duration of the supine phase of the rollover.

\begin{tabular}{lrrrrrr}
\hline & \multicolumn{1}{c}{$\boldsymbol{\beta}$} & $\mathbf{S E}$ & $\mathbf{Z}$ & $\mathbf{P}$ & & $\mathbf{9 5 \%} \mathbf{C l}$ \\
\cline { 2 - 7 } ative height & 73.716 & 9.107 & 8.090 & 0.000 & 55.867 & 91.564 \\
Istant & -18.957 & 9.317 & -2.030 & 0.042 & -37.218 & -0.697 \\
\hline
\end{tabular}

Log restricted likelihood $=2249.953$, Wald $\mathrm{Chi}^{2}{ }_{1}=65.52, \mathrm{P}<0.0001$

\subsubsection{Data set 2: YouTube dogs}

\subsubsection{The occurrence of rollovers during play}

Rollovers were recorded from all dyads during the play bouts, with 27 of the 40 dogs doing so. Fifteen of the dogs that did rollover were in similarsized pairs, while 12 were in pairs that differed in size. The mean play bout length was $114.79 \mathrm{~s}( \pm 96.9 \mathrm{SD})$. There was no significant difference between play bout lengths for similarly- and dissimilarly-sized pairs $(\mathrm{t}=1.23,15.3 \mathrm{df}$, $\mathrm{P}>0.05)$. I ran a multiple regression to assess the effect of the relative size of partners (similar, dissimilar) and the duration of the play bout on the frequency with which rollovers occurred during a bout (Table 4). While relative size did not enter the model, there was a positive relationship between bout length and the number of rollovers. 
Table 4. The relationship between the relative size of play partners and the duration of the play bout on the frequency with which rollovers were performed.

\begin{tabular}{lllllrl}
\hline & $\boldsymbol{\beta}$ & $\mathbf{S E}$ & $\mathbf{t}$ & $\mathbf{P}$ & $\mathbf{9 5 \%} \mathbf{C l}$ & \\
\hline & & & & & & \\
Play bout duration & 0.061 & 0.014 & 4.450 & 0.000 & 0.032 & 0.090 \\
Relative size & 1.300 & 2.586 & 0.500 & 0.622 & -4.156 & 6.757 \\
Constant & -1.522 & 2.392 & -0.640 & 0.533 & -6.568 & 3.524 \\
\hline
\end{tabular}

$\mathrm{F} 2,17=11.54, \mathrm{P}=0.0007$, Adj. $\mathrm{R}^{2}=0.57$

\subsubsection{Duration of the supine phase of the rollover}

First the duration of the supine phase of the rollover was assessed in order to discern if it was longer in play partners of different statures. This was completed by running a GLMM with dog identity as a random effect (Table 5). No effect was found to exist. Second, the analysis was repeated for dyads of different sizes, in order to determine whether the smaller of the two partners was more likely to sustain the supine position for longer (Table 6). No effect was found to exist. 
Table 5. The effects of the relative size of play partners (similar, dissimilar) on the duration of the supine phase of the rollover.

\begin{tabular}{lllllll}
\hline & B & SE & Z & P & $95 \% \mathbf{C l}$ & \\
\hline $\begin{array}{l}\text { Relative } \\
\text { Size }\end{array}$ & 0.098 & 7.784 & 0.010 & 0.990 & -15.158 & 15.354 \\
Constant & 12.730 & 5.640 & 2.260 & 0.024 & 1.675 & 23.784 \\
\hline
\end{tabular}

Log restricted-likelihood $=-580.99$, Wald $\mathrm{Chi}^{2}{ }_{1}=0.00 \quad \mathrm{P}=0.99$

Table 6. The effect of relative partner size on the duration of the supine phase of the rollover in dyads of dissimilarly sized dogs.

\begin{tabular}{lllllll}
\hline \multicolumn{2}{c}{ B } & SE & Z & P & 95\% Cl & \\
\hline Relative size & 13.768 & 9.681 & 1.420 & 0.155 & -5.206 & 32.742 \\
Constant & 6.137 & 6.646 & 0.920 & 0.356 & -6.889 & 19.163 \\
\hline
\end{tabular}

Log restricted-likelihood $=-205.17$, Wald $\mathrm{Chi}^{2}{ }_{1}=2.02, \mathrm{P}=0.155$

\subsubsection{Duration of the supine phase}

To assess the prediction that the supine phase of the rollover will be prolonged if used for submission, I used all the available data to compare the distribution of durations against the normal distribution (Figure 5). Both data sets differed significantly from the normal distribution (Shapiro-Wilk test: $\mathrm{W}_{\text {Target } \operatorname{dog}}=0.81, \mathrm{~N}=87, \mathrm{P}<0.0001 ; \mathrm{W}_{\text {YouTube dogs }}=0.56, \mathrm{~N}=161$, 
$\mathrm{P}<0.0001$ ), exhibiting marked positive skew. This suggests that durations were short, not prolonged.
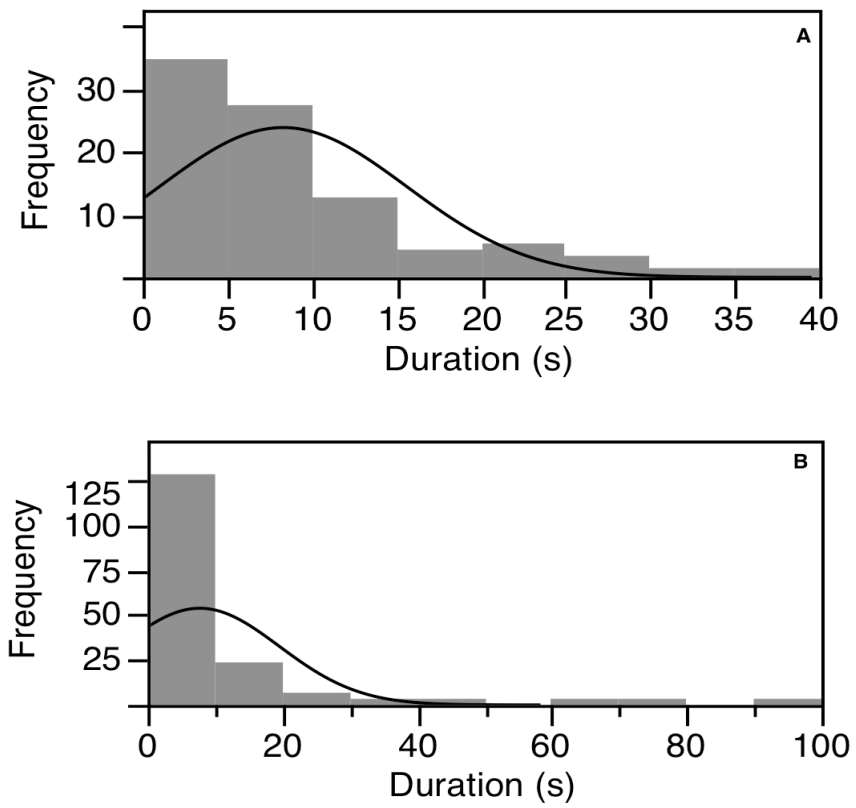

Figure 5. The frequency distributions of the duration of the supine phase of the rollover for (A) Data set 1 and (B) Data set 2. The expected normal distributions for each data set are presented as black lines.

\subsection{The frequency of different types of rollovers}

As notated from the EWMN analyses, rollovers occurred in several different contexts, with three of the four discerned involving a clear social context. Nonetheless, it is possible that since only a subset of rollovers were analyzed using EWMN, some of the rollovers occurring during play fighting may have been submissive. Therefore, all the rollovers that occurred in both data sets were scored as to whether they occurred in association with launching an attack (offensive), evading a nape bite (defensive), rolling in front of a potential partner (solicitation) or rolling over in a non-social context 
(other). In addition, any rollover that occurred in the close proximity of a partner, but not involving any of the other contexts was also used as a possible category of rollover (submissive). As can be seen from Figure 6, most rollovers were defensive and none of the 248 rollovers was submissive. Chisquare analyses revealed that the distribution was significantly non-random, based on treating each category as equally likely (data set $1: \mathrm{X}^{2}=235.64, \mathrm{df}=$ $4, \mathrm{p}<0.001$; data set $\left.2: \mathrm{X}^{2}=376.14, \mathrm{df}=4, \mathrm{p}<0.001\right)$. Because the overall values used were contributed unevenly by different dogs the first rollover from each dog (excluding the play partner from data set 1) was used to determine whether the modal category shown in Figure 6 was also the case for individual dogs. Individual dogs from both data sets were combined. From the first rollover in the 34 dogs available for this analysis, $79.4 \%$ were defensive rollovers, a significant non-random distribution $\left(\mathrm{X}^{2}=11.76\right.$, $\mathrm{df}=1$, $\mathrm{p}<0.01)$

It was also possible that once rolling over onto its back to defend the nape, the performer could remain passive regardless of the subsequent actions of the partner and, if so, this could signify that supine position could still be being used for submission after the initial defensive function. This possible submissive role would be underestimated in Figure 6. Therefore, given that the defensive rollovers were the modal form of rolling over, the subsequent action by the performer was scored once it lay on its back. If 
submissive, once on its back the performer should remain passive. However, if rotating to a supine position is defensive, then the performer should track the movements of the partner by keeping its mouth oriented towards the partner's face, thereby blocking attacks by the partner. For both data set 1 (78 defensive rollovers) and data set 2 (128 defensive rollovers), 100\% of the rollovers led to the supine dog blocking the movements of the partner actively. Indeed, more than half of these blocking actions were followed by the supine dog biting the partner $(52.3 \%$ for data set $1 ; 60 \%$ for data set 2$)$.

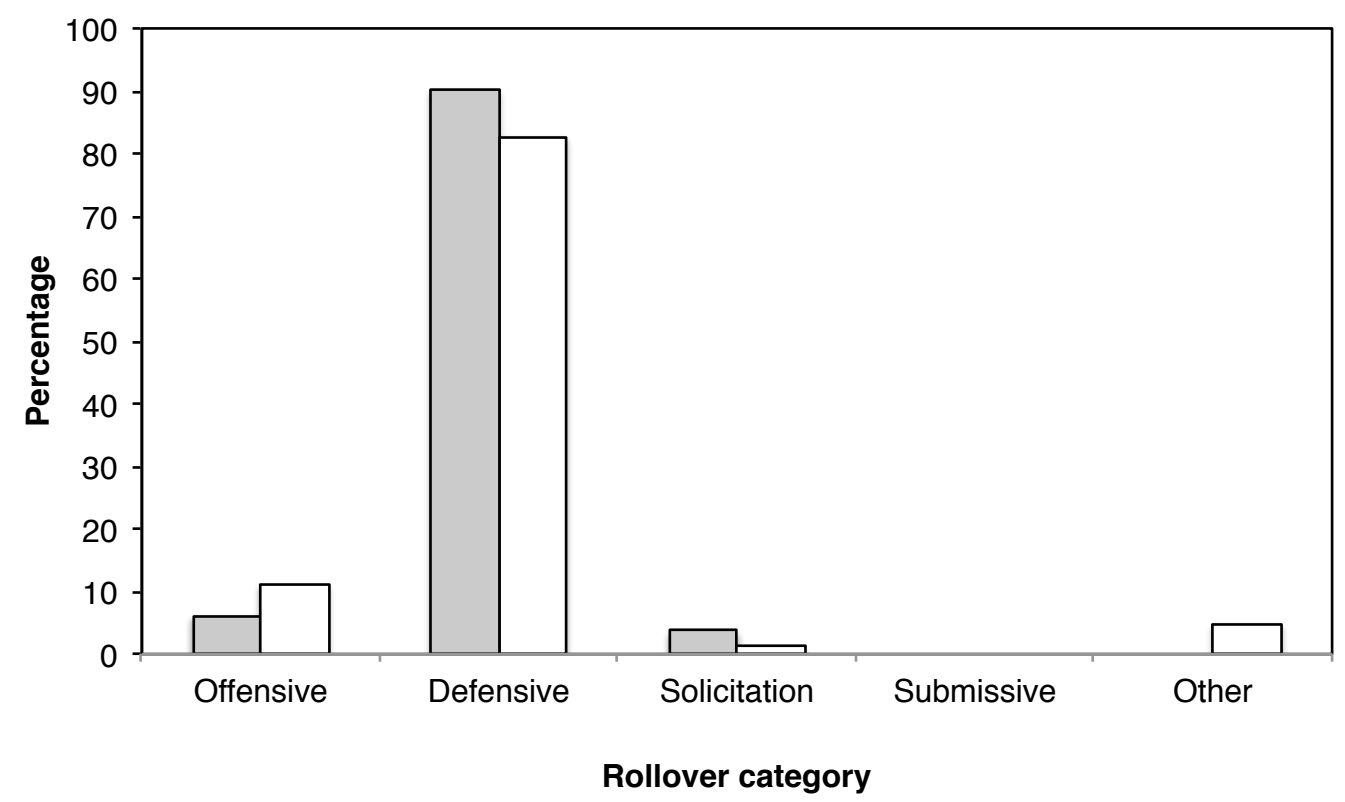

Figure 6. The percentages of the five possible forms of rollovers are shown for the two data sets. The distribution from data set 1 (Target dog: $N=87$ ) is shown as the first column (shaded bars) and that from data set 2 (YouTube dogs: $\mathrm{N}=$ 161 ) is shown in the second column (white bars). 


\section{Chapter 5: Discussion}

Rolling over on to the back and adopting a supine position occurs frequently during the play fighting of juvenile and adult dogs (Bauer et al., 2007; Fox, 1969). As this posture can be used as a submissive gesture in both dogs and wolves (Lorenz, 1942; Schenkel, 1967), it has been used to identify asymmetries in the relationships between play partners in dogs (Bekoff, 1974; Ward et al., 2008). However, as shown by studies of play in juvenile wolves, when the correlated movements of both partners are considered, actions leading to the supine position may be, in some cases, better interpreted as combat actions (Havkin et al., 1985). Although not analysed in the same way, a study on the play of adult wolves indicates that some of the actions performed during play may similarly be better interpreted as combat tactics rather than as submissive signals (Cordoni, 2009). Moreover, this interpretation would be consistent with studies of play fighting in a wide array of species from several taxa (e.g., Aldis, 1975; Pellis, 1988; Owens, 1975a, b; Pellis et al., 2014; Reinhart et al., 2010; Symons, 1978). The results from the present study show that rolling over to supine in the play fighting of adult dogs is most consistent with this maneuver being used as a combat tactic.

To be used as a submissive gesture, we would expect the supine position to be adopted by the smaller or weaker dog, yet, if anything, some of the present 
data indicate that the bigger dog is more likely to do so. Similarly, if used as a submissive gesture, the duration of remaining supine should be long, yet the present data show that they are skewed to the short end of the distribution. Also, if submissive, there should be an asymmetry in the duration of the supine position between pair mates. Our data provide no evidence for this. Detailed analyses of when and how rollovers occur during play fights revealed that $80-90 \%$ of them were deployed as a combat tactic, either to lunge and bite at the partner's throat (offensive) or to evade a bite to the nape of the neck (defensive). Indeed, the large majority of the rollovers were defensive.

In some rodents, such as mice and rats, turning to supine is used during serious fighting to avoid bites to the rump area (Blanchard et al., 1977; Blanchard et al., 1979; Pellis et al., 1992). Once on their back, they may lie motionless (Grant et al., 1963), which seems to inhibit further attack (Thor et al., 1981). However, while both rats and mice use the manoeuvre as a defensive tactic, mice are less likely to use a supine posture during submission, because the attacker in this species is more likely to switch from directing bites to the rump to biting at the more vulnerable ventrum (Blanchard et al., 1979). Thus, mice will rapidly turn to supine to protect their rump, but then immediately roll back to a prone position before fleeing (Pellis et al., 1992). Therefore, even when the initial rotation to supine is a 
defensive manoeuvre, once supine, it can be maintained as a submissive position. The same could be true for dogs during play fighting.

Yet, as indicated by the analyses of the identity of which partner is most likely to rollover and the data on the duration of remaining supine, the present findings are not consistent with the sustained supine position indicating submission. Another possible course of action, reported in rats, provides some potential insight into the current findings on dogs. Although, once they have rotated to supine, rats will occasionally remain completely motionless (Grant, 1963), they are also likely to move their heads slowly so as to be able to continue to face the mouth of their opponent; this can lead to a defensive bite to the side of their face if the opponent attempts to bite the performer (Blanchard et al., 1977). That is, while remaining supine, the animal can continue to manoeuvre in a way that provides a defense against further attack. Similarly, we have shown that, once they rotated to supine to defend their napes, the dogs did not remain passive. Rather, like the rats, they moved their heads in order to track the position of their partner's face and, indeed, in a majority of cases, coupled such tracking with a biting attack that was directed at the partner's face or neck. That is, even when they did end on their backs as a defensive action, their subsequent behaviour was not consistent with the supine position being used as a submissive gesture. Therefore, in all respects, the rollovers that we observed and analysed are 
consistent with their being used as combat tactics, not as signals of submission.

There were a small number of rollovers $(\sim 5 \%)$ that were consistent with their being signals rather than as tactics, but these were used in a way that made them likely to be play solicitation gestures. The performer approached and rolled in front of its partner - an action, in other species, reported to attract a playful response from the partner (e.g., Palagi, 2008; LeResche, 1976; Pellis et al., 2014). Moreover, such rollovers could be coupled with play bows and pawing the partner, both of which have established play signaling or solicitation functions (Bekoff, 1995; Horowitz, 2009). Therefore, while a small percentage of rollovers served an apparently communicatory purpose, they did not function as submission signals. 


\section{Conclusion}

In the present study, none of the 'rollovers to supine' were consistent with their being used as gestures of submission by playing dogs. Rather, a large majority was used tactically during play fighting, while the few that were used as signals were used to solicit playful contact. Therefore, the present study questions the assumptions that rollovers occurring during play signify submission and that asymmetries in their use necessarily reflects differing social status (Bauer et al., 2007; Fox, 1969; Ward et al., 2008). It is possible, however, that in studies where dogs have an established, prior relationship with each other, some rollovers could function to indicate submission (Ward et al., 2008). Nonetheless, as the analyses presented here make clear, this must be demonstrated empirically, not assumed.

This has implications for how dogs negotiate their playful interactions. Two means of ensuring that play fights do not escalate into serious fights have been proposed. First, during play, the animals follow what has been termed the "50-50" rule (Altmann, 1962), whereby both partners have near equal opportunity to get the upper hand during an encounter, and so ensure reciprocity. Indeed, a game theory simulation showed that play fights become increasingly likely to escalate the further from parity the interactions deviate 
(Dugatkin et al., 2003). Second, an animal uses play signals to telegraph to another animal that the impending contact will be playful (Bekoff, 1995) or to signify that a potentially ambiguous manoeuvre during play is actually playful (Aldis, 1975). The two, of course, can work in concert, with play signals being used in situations in which there may be some ambiguity as to whether the rule of reciprocity is being followed (Pellis et al., 1996).

The considerable asymmetry in the rates of adopting the supine position by playing dogs (Ward et al., 2008) led to the 50-50 rule being challenged as a necessary component in the maintenance of play. At the least, such marked asymmetry would suggest that some species can tolerate considerable deviation from parity and still remain playful (Bauer et al, 2007). Indeed, while juvenile rats engage in actions that tend to mitigate any one partner maintaining the most advantageous position, so ensuring that interactions are reciprocal (Foroud et al., 2002), adult playful interactions can be markedly asymmetrical (Pellis et al., 1993). However, as shown here, an asymmetry in the adoption of a supine posture need not reflect an asymmetry in the relationship structure of playing dogs. Such asymmetries are more likely to emerge from individual differences in playfulness and play style (Pellis et al., 1992), set in the context of the particularities presented by the dyad itself. 


\section{References}

Abrantes, R. (2005). Evolution of Canine Social Behavior. Dogwise Publishing.

Aldis, O. (1975). Play-fighting. New York: Academic Press.

Altmann, S. A. (1962). Social behavior of anthropoid primates: Analysis of recent concepts. In E. L. Bliss (Ed.), Roots of behavior (pp. 277-285). New York: Harper.

Bauer, E. B., \& Smuts, B. B. (2007). Cooperation and competition during dyadic play in domestic dogs, Canis familiaris. Animal Behaviour, 73(3), 489499.

Bekoff, M. (1972). The development of social interaction, play, and metacommunication in mammals: an ethological perspective. Quarterly Review of Biology, 412-434.

Bekoff, M. (1974). Social play in coyotes, wolves, and dogs. Bioscience, 24(4), $225-230$. 
Bekoff, M. (1976). Animal play: problems and perspectives. In Perspectives in ethology (pp. 165-188). Springer US.

Bekoff, M., \& Byers, J. A. (1981). A critical reanalysis of the ontogeny and phylogeny of mammalian social and locomotor play: An ethological hornet's nest. Behavioral development: The Bielefeld interdisciplinary project, 296337.

Bekoff, M. (1995). Play signals as punctuation: The structure of social play in canids. Behaviour, 419-429.

Bekoff, M., Allen, C., \& Burghardt, G. M. (Eds.). (2002). The cognitive animal: Empirical and theoretical perspectives on animal cognition. Mit Press.

Biben, M. (1998). Squirrel monkey play fighting: making the case for a cognitive training function for play. Animal play: Evolutionary, comparative, and ecological perspectives, 161-182.

Blanchard, R. J., Blanchard, D. C., Takahashi, T., \& Kelley, M. J. (1977). Attack and defensive behaviour in the albino rat. Animal Behaviour, 25, 622634. 
Blanchard, R. J., O'Donnell, V., Blanchard, D. C., (1979). Attack and defensive behaviors in the albino mouse (Mus musculus). Aggressive Behaviour. 5, 341-352.

Boitani, L., Ciucci, P., \& Ortolani, A. (2007). Behaviour and social ecology of free-ranging dogs. The Behavioural Biology of Dogs. CAB International, Wallingford, UK, 147-165.

Bradshaw, J. W., Blackwell, E. J., \& Casey, R. A. (2009). Dominance in domestic dogs—useful construct or bad habit?. Journal of Veterinary Behavior: Clinical Applications and Research, 4(3), 135-144.

Bradshaw, J. (2011). Dog sense: How the new science of dog behavior can make you a better friend to your pet. Basic Books.

Burghardt, G. M. (2005). The genesis of animal play: Testing the limits. Mit Press.

Coppinger, R., Glendinning, J., Torop, E., Matthay, C., Sutherland, M., \& Smith, C. (1987). Degree of behavioral neoteny differentiates canid polymorphs. Ethology, 75(2), 89-108. 
Coppinger, R., \& Coppinger, L. (2001). Dogs: A startling new understanding of canine origin, behavior \& evolution. Simon and Schuster.

Cordoni, G. (2009). Social play in captive wolves (Canis lupus): not only an immature affair. Behaviour, 146(10), 1363-1385.

Darwin, C. (1998). The expression of the emotions in man and animals. Oxford University Press.

Dugatkin, L. A., \& Bekoff, M. (2003). Play and the evolution of fairness: a game theory model. Behavioural processes, 60(3), 209-214.

Fagen, R. (1981). Animal play behavior (p. 684). New York: Oxford University Press.

Fatjo, J., Amat, M., Mariotti, V. M., de la Torre, J. L. R., \& Manteca, X. (2007). Analysis of 1040 cases of canine aggression in a referral practice in Spain. Journal of Veterinary Behavior: Clinical Applications and Research, 2(5), 158-165.

Foroud, A., \& Pellis, S. M. (2002). Development of "anchoring" in the play fighting of rats: Evidence for an adaptive age-reversal in the juvenile phase. International Journal of Comparative Psychology, 15(1). 
Fox, M. W. (1969). The anatomy of aggression and its ritualization in Canidae: a developmental and comparative study. Behaviour, 242-258.

Fox, M. W. (1970). A comparative study of the development of facial expressions in canids; wolf, coyote and foxes. Behaviour, 49-73.

Fox, M. (1971). Behaviour of wolves dogs and related canids. Dogwise Publishing.

Frank, H., \& Frank, M. G. (1982). On the effects of domestication on canine social development and behavior. Applied Animal Ethology, 8(6), 507-525.

Freedman, A.H., Gronau, I., Schweizer, R.M., Vecchyo, D., Han. E., Silva, P.M., Galaverni, M., Fan, Z., Marx, P., Lorente-Galdos, B., Beale, H., Ramirez, O., Hormozdiari, F., Alkan, C., Vila`, C., Squire, K., Geffen, E., Kusak, J., Boyko, A.R., Parker, H.G., Lee, C., Tadigotla, V., Siepel, A., Bustamante, C.D., Harkins, T.T., Nelson, S.F., Ostrander, E.A., MarquesBonet, T., Wayne, R.K., Novembre J. (2014). Genome sequencing highlights the dynamic early history of dogs. PLoS Genetics 10: e1004016. 
Golani, I. (1976). Homeostatic motor processes in mammalian interactions: a choreography of display. In Perspectives in ethology (pp. 69-134). Springer US.

Goodwin, D., Bradshaw, J. W., \& Wickens, S. M. (1997). Paedomorphosis affects agonistic visual signals of domestic dogs. Animal Behaviour, 53(2), 297-304.

Grant, E. C. (1963). An analysis of the social behaviour of the male laboratory rat. Behaviour 21, (260-281).

Grant, E. C., Mackintosh, J. M. (1963). A comparison of some social postures of some common laboratory rodents. Behaviour 21, (246-259).

Handelman, B. (2012). Canine behavior: A photo illustrated handbook. Dogwise Publishing.

Harrington, F. H., \& Asa, C. S. (2003). Wolf communication. L. D. Mech, \& L. Boitani (Eds.). Chicago, IL: University of Chicago Press.

Hart, B. L., \& Miller, M. F. (1985). Behavioral profiles of dog breeds. Journal of the American Veterinary Medical Association, 186(11), 1175-1180. 
Havkin, Z., \& Fentress, J. C. (1985). The form of combative strategy in interactions among wolf pups (Canis lupus). Zeitschrift für Tierpsychologie, 68(3), 177-200.

Horowitz, A. (2009). Attention to attention in domestic dog (Canis familiaris) dyadic play. Animal Cognition, 12(1), 107-118.

Horowitz, A. (2010). Inside of a dog: What dogs see, smell, and know. Simon and Schuster.

Leresche, L. A. (1976). Dyadic play in hamadryas baboons. Behaviour, 190205.

Lindsay, S.R. (2000). Handbook of Applied Dog Behavior and Training, Volume 1, Adaptation and Learning. Iowa State University Press, Ames, Iowa.

Lorenz, K. (1942). Die angeborener Forme möglicher Erfahrung. Z. Tierpsychol. 5: 235-409.

Lorenz, K. (1954). Man Meets Dog, trans. Wilson, M., Methuen, London. 
McLeod, P. J., \& Fentress, J. C. (1997). Developmental changes in the sequential behavior of interacting timber wolf pups. Behavioural processes, $39(2), 127-136$.

Mech, L.D. (1970). The Wolf. Natural History Press, Garden City, NY

Mech, L.D. (1999). Alpha status, dominance, and division of labor in wolf packs. Canadian Journal of Zoology, 77(8), 1196-1203.

Miklósi, Á. (2007). Dog behaviour, evolution, and cognition. Oxford University Press.

Moran, G., Fentress, J. C., \& Golani, I. (1981). A description of relational patterns of movement during 'ritualized fighting'in wolves. Animal Behaviour, 29(4), 1146-1165.

Owens, N. W. (1975a). Social play behaviour in free-living baboons, Papio anubis. Animal Behaviour, 23, 387-408.

Owens, N. W. (1975b). A comparison of aggressive play and aggression in free-living baboons, Papio anubis. Animal behaviour, 23, 757-765. 
Packard, J. M. (2003). Wolf behavior: reproductive, social, and intelligent. Wolves: behavior, ecology, and conservation. University of Chicago Press, Chicago, Illinois, USA, 35-65.

Pal, S. K., Ghosh, B., \& Roy, S. (1998). Agonistic behaviour of free-ranging dogs (Canis familiaris) in relation to season, sex and age. Applied Animal Behaviour Science, 59(4), 331-348.

Palagi, E. (2008). Sharing the motivation to play: the use of signals in adult bonobos. Animal Behaviour, 75(3), 887-896.

Pellis, S. M. (1988). Agonistic versus amicable targets of attack and defense: Consequences for the origin, function, and descriptive classification of play-fighting. Aggressive Behavior, 14(2), 85-104.

Pellis, S. M., \& McKenna, M. M. (1992). Intrinsic and extrinsic influences on play fighting in rats: effects of dominance, partner's playfulness, temperament and neonatal exposure to testosterone propionate. Behavioural brain research, 50(1), 135-145. 
Pellis, S. M., \& Pellis, V. C. (1987). Play-fighting differs from serious fighting in both target of attack and tactics of fighting in the laboratory rat Rattus norvegicus. Aggressive Behavior, 13(4), 227-242.

Pellis, S. M., \& Pellis, V. C. (1996). On knowing it's only play: the role of play signals in play fighting. Aggression and Violent Behavior, 1(3), 249-268.

Pellis, S. M., Pellis, V. C., McKenna, M. M. (1993). Some subordinates are more equal than others: Play fighting amongst adult subordinate male rats. Aggress. Behav. 19, 385-393.

Pellis, S. M., Pellis, V. C., Manning, C. J., Dewsbury, D. A. (1992). Supine defense in the intraspecific fighting of male house mice Mus domesticus. Aggress. Behav. 18, 373-379.

Pellis, S. M., Blundell, M. A., Bell, H. C., Pellis, V. C., Krakauer, A. H., \& Patricelli, G. L. (2013). Drawn into the vortex: The facing-past encounter and combat in lekking male greater sage-grouse (Centrocercus urophasianus). Behaviour, 150, 1567-1599.

Pellis, S. M., Pellis, V. C., Barrett, L., \& Henzi, S. P. (2014). One good turn deserves another: Combat versus other functions of acrobatic maneuvers in 
the play fighting of vervet monkeys (Chlorocebus aethiops). Animal Behavior and Cognition, 1(2), 128-143.

Price, E. O. (1999). Behavioral development in animals undergoing domestication. Applied Animal Behaviour Science, 65(3), 245-271.

Reinhart, C. J., Pellis, V. C., Thierry, B., Gauthier, C. A., VanderLaan, D. P., Vasey, P. L., \& Pellis, S. M. (2010). Targets and tactics of play fighting: Competitive versus cooperative styles of play in Japanese and Tonkean macaques. International Journal of Comparative Psychology, 23(2).

Robinson, B. W., \& Doyle, R. W. (1990). Phenotypic correlations among behaviour and growth variables in tilapia: implications for domestication selection. Aquaculture, 85(1), 177-186.

Ruzzante, D. E., \& Doyle, R. W. (1993). Evolution of social behavior in a resource-rich, structured environment: selection experiments with medaka (Oryzias latipes). Evolution, 456-470.

Ruzzante, D. E. (1994). Domestication effects on aggressive and schooling behavior in fish. Aquaculture, 120(1), 1-24.

SAS Institute (2012). JMP Start Statistics (Duxbury, Pacific Grove, CA). 
Schenkel, R. (1967). Submission: its features and function in the wolf and dog. American Zoologist, 7(2), 319-329.

Scott, J. P. (1956). The analysis of social organization in animals. Ecology, $213-221$.

Scott, J. P. (Ed.). (1965). Genetics and the Social Behavior of the Dog. University of Chicago Press.

Serpell, J. (Ed.). (1995). The domestic dog: its evolution, behaviour and interactions with people. Cambridge University Press.

StataCorp. (2013). Stata Statistical Software: Release 13. College Station, TX: StataCorp LP.

Symons, D. (1978). Play and aggression: A study of rhesus monkeys. New York: Columbia University Press.

Thor, D. H., Wainwright, K. L., \& Holloway, W. R. (1981). Attraction to mobile and immobile conspecifics. Animal Learning \& Behavior, 9(3), 363367. 
van Kerkhove, W. (2004). A fresh look at the wolf-pack theory of companionanimal dog social behavior. Journal of Applied Animal Welfare Science, 7(4), 279-285.

Ward, C., Bauer, E. B., \& Smuts, B. B. (2008). Partner preferences and asymmetries in social play among domestic dog, Canis lupus familiaris, littermates. Animal Behaviour, 76(4), 1187-1199.

Watson, D. M., \& Croft, D. B. (1996). Age-related Differences in Playfighting Strategies of Captive Male Red-necked Wallabies (Macropus rufogriseus banksianus). Ethology, 102(2), 336-346.

Wayne, R. K., \& Ostrander, E. A. (1999). Origin, genetic diversity, and genome structure of the domestic dog. BioEssays, 21(3), 247-257.

Zimen, E. (1982). A wolf pack sociogram. Wolves of the world. Edited by FH Harrington, and PC Paquet. Noyes Publishers, Park Ridge, NJ, 282-322. 